PICH, AN ATP-DEPENDENT CHROMATIN REMODELING

PROTEIN, TRANSCRIPTIONALLY CO-REGULATES

\section{OXIDATIVE STRESS RESPONSE}

Anindita Dutta, Apurba Das, Deepa Bisht, Vijendra Arya and Rohini Muthuswami\#

Chromatin Remodeling Laboratory, School of Life Sciences, JNU, New Delhi-110067, India

\# Corresponding Author: Rohini Muthuswami, Room \# 306, School of Life Sciences, JNU, New Delhi-110067, India. Email: rohini_m@mail.jnu.ac.in

Running title: $\mathrm{PICH}$ is a transcriptional co-regulator

Keywords: PICH, Nrf2, oxidative stress, epigenetics, ATP-dependent chromatin remodeling. 


\section{ABSTRACT}

22 Cells respond to oxidative stress by elevating the levels of antioxidants, signaling, and transcriptional regulation often implemented by chromatin remodeling proteins. The study presented in this paper shows that the expression of PICH, an ATP-dependent chromatin remodeler, is upregulated during oxidative stress in HeLa cells. We also show that PICH regulates the expression of Nrf2, a transcription factor regulating antioxidant response, both in the absence and presence of oxidative stress. In turn, Nrf2 regulates the expression of $\mathrm{PICH}$ in the presence of oxidative stress. Both PICH and Nrf2 together regulate the expression of antioxidant genes and this transcriptional regulation is dependent on the ATPase activity of PICH. In addition, H3K27ac modification also plays a role in activating transcription in the presence of oxidative stress. Co-immunoprecipitation experiments show that PICH and Nrf2 interact with H3K27ac in the presence of oxidative stress.

Mechanistically, PICH recognizes ARE sequences present on its target genes and introduces a conformational change to the DNA sequences leading us to hypothesize that PICH regulates transcription by remodeling DNA. PICH ablation leads to reduced expression of Nrf2 and impaired antioxidant response leading to increased ROS content, thus, showing $\mathrm{PICH}$ is essential for the cell to respond to oxidative stress. 
INTRODUCTION

The ATP-dependent chromatin remodeling proteins dynamically alter the chromatin architecture to enable transcription factors to access the genomic DNA and thereby mediate transcription and repair [1]. Organismal life encounters reactive oxidants from internal metabolism as well as from environmental toxicant exposure resulting in oxidative stress due to imbalance between reactive oxygen species (ROS) and antioxidants. The role of epigenetic modulators in combating oxidative stress has been well-documented. For example, oxidative stress has been shown to activate histone acetyltransferases and inhibit histone deacetylase activity [2]. Studies have also shown that BRG1, an ATP-dependent chromatin remodeling protein, interacts with $\mathrm{Nrf} 2$, a transcription factor, to regulate the expression of $\mathrm{HO}-1$ in response to oxidative stress [3]. CHD6 too is an important regulator of oxidative stress [4].

like helicase belonging to the ATP-dependent chromatin remodeling protein family [5-7].

The protein has been identified as a strong binding partner and substrate of PLK-1 that localizes at the kinetochores [5]. Immunofluorescence staining has revealed that PICH is mostly concentrated in between kinetochores in prometaphase cells while in metaphase cells the protein localizes to numerous short threads that stretch between the sister-kinetochores of the aligned chromosomes [5]. The protein has been shown to respond to the tensiondependent alterations in DNA topology by resolving the ultrafine bridges generated in between the centromeres of the segregating chromatids and regulates the spindle attachment checkpoint [8]. PICH depleted cells show chromosomal abnormalities, dead cells, bi-nuclei, and multi-nuclei formation [9]. The protein is found to be overexpressed in many cancers and silencing the expression of PICH has shown to inhibit their proliferation [10,11]. Studies have also shown that the protein interacts with BEND3 as well as with topoisomerases; however, the protein has not been shown to reposition/remodel nucleosomes $[9,12,13]$. 
Studies over the past decade have established the role of Nrf2 in combating oxidative stress in cells [16]. In cells, in the absence of oxidative stress, Nrf2is ubiquitinated by Keap1 and degraded by the proteasome pathway $[17,18]$. In the presence of oxidative stress, Keap1 is inactivated, leading to the release of Nrf2 which migrates to the nucleus and activates the expression of antioxidant genes by binding to the Antioxidant Responsive Element (ARE) present on the promoters of the antioxidant genes [17,18]. Knockout of Nrf2 in mice increases their susceptibility to chemical toxins and the mice exhibit disease conditions associated with oxidative pathology [19]. provide evidence that $\mathrm{PICH}$ regulates the antioxidant response in HeLa cells under oxidative stress. PICH also regulates the expression of Nrf2 and together with Nrf2 and H3K27ac appears to drive the expression of the antioxidant genes. We also show that PICH induces a conformational change in the DNA structure in an ATP-dependent manner, thus, provide a possible mechanism for transcriptional co-regulation mediated by this protein. 


\section{RESULTS}

\section{PICH expression is upregulated when cells are exposed to oxidative stress:}

Previously, we reported that BRG1 and SMARCAL1 both belonging to the ATP-dependent chromatin remodeling protein family co-regulate each other's expression on treatment with doxorubicin [20]. To investigate whether this regulation is universal and occurs on induction of any type of DNA damage, HeLa cells were subjected to oxidative stress generated endogenously by transfecting cells with a plasmid encoding for D-amino acid oxidase (DAAO). The cells, $36 \mathrm{~h}$ post-transfection, were treated with $25 \mathrm{mM}$ D-serine for $10 \mathrm{~min}$ [21] resulting in the production of $\mathrm{H}_{2} \mathrm{O}_{2}$ within the cell by the action of DAAO on D-serine. ROS production was confirmed by DCFDA staining (Fig. S1A and B). The treated cells were harvested, and the RNA was isolated to analyze the expression of $B R G 1$ and SMARCAL1 by qPCR. Surprisingly, the expression of BRG1 and SMARCAL1 were unchanged but the expression of $P I C H$, an ATP-dependent chromatin remodeler, and Nrf2, a transcription factor, was upregulated (Fig S1C). The changes in the transcript level were confirmed by western blot (Fig. S1D and E). Further, the expression of antioxidant genes $C A T$, GPX1, GSR, and TXNRD1was found to be upregulated while SOD1 was unchanged (Fig. S1F). Concomitantly, catalase activity was also found to be upregulated (Fig S1G). Untransfected HeLa cells treated with D-serine did not exhibit these changes in the transcript indicating that this molecule by itself is not contributing to oxidative stress or changes thereof (Fig. S1H). Taken together, the experimental results indicated that PICH expression was upregulated on oxidative stress.

To confirm the upregulation of PICH in response to oxidative stress, HeLa cells were treated with $100 \mu \mathrm{M} \mathrm{H}_{2} \mathrm{O}_{2}$ and the expression was analyzed as a function of time [22]. Analysis showed that the expression of $\mathrm{PICH}$ was upregulated 20 min post-treatment in comparison to the untreated HeLa cells (Fig. 1A). The upregulation was confirmed by 
western blot (Fig. 1B and C). As the first peak of PICH expression was at 20 min posttreatment as compared to the untreated HeLa cells, all the experiments described henceforth were performed after treating HeLa cells with $100 \mu \mathrm{M} \mathrm{H}_{2} \mathrm{O}_{2}$ for 20 min. Under this condition, the production of ROS was confirmed by staining the cells with DCFDA (Fig. 1D and E). $\gamma \mathrm{H} 2 \mathrm{AX}$ foci formation confirmed DNA damage was also induced under this condition (Fig. 1F and G).

Next, the expression of $N r f 2, B R G 1$, and $S M A R C A L 1$ was analyzed after treatment with $100 \mu \mathrm{M} \mathrm{H}_{2} \mathrm{O}_{2}$ for $20 \mathrm{~min}$. As expected, $N r f 2$ expression was upregulated on the generation of oxidative stress exogenously (Fig. 1H). Interestingly, unlike the endogenous pathway, on exogenous treatment with $\mathrm{H}_{2} \mathrm{O}_{2}, B R G 1$ and SMARCALl were upregulated along with $N r f 2$ (Fig. 1H). This upregulation was also confirmed by western blots (Fig. 1I and J). The dichotomy between the endogenous and exogenous pathways was further accentuated by analysis of the expression of antioxidant genes. Unlike the endogenous pathway, where SOD1 was unchanged and GSR was upregulated, in the exogenous pathway, SODI was upregulated while GSR was unchanged (compare Fig. 1K with Fig. S1F). As it is not possible to compare the amount of ROS produced under these two conditions, therefore, a direct comparison with the amount of ROS produced and the pathway activated cannot be made. We, however, noted that catalase activity was upregulated when cells were treated with D-serine after $D A A O$ transfection as well as with hydrogen peroxide (Fig. 1L and Fig. S1G).

\section{PICH expression on oxidative stress is cell line dependent: Various reports have} suggested that the expression of a given chromatin remodeling protein in response to stress is cell line-specific [3,23]. To understand whether PICH expression in response to oxidative stress was also dependent on the cell line, transcript levels were analyzed in SiHa and HEK293 cell lines in response to $100 \mu \mathrm{M} \mathrm{H}_{2} \mathrm{O}_{2}$ treatment given for 20 min. In HEK293 
cells, PICH and Nrf2 expression were upregulated like in HeLa cells while in SiHa cells, PICH transcript level was downregulated and Nrf2 was upregulated (Fig. S1I and J). Thus, the expression of PICH in response to oxidative stress does appear to be cell line-specific. In this paper, the connection between $\mathrm{PICH}, \mathrm{Nrf} 2$, and antioxidant genes on treatment with $\mathrm{H}_{2} \mathrm{O}_{2}$ in HeLa cells has been explored.

PICH regulates the expression of Nrf2 in HeLa cells in the absence and presence of

oxidative stress: To understand whether PICH is necessary for the upregulation of $\mathrm{Nrf} 2$, on oxidative stress, shRNA against the 3' UTR of PICH was used to downregulate the expression of this gene in HeLa cells. Downregulation of PICH led to downregulation of Nrf2 both in the absence $(\mathrm{P}$-value $=3 \mathrm{E}-10)$ and presence $(\mathrm{P}$-value $=2.21 \mathrm{E}-06)$ of $\mathrm{H}_{2} \mathrm{O}_{2}$, indicating PICH regulates Nrf2 expression regardless of oxidative stress (Fig. S2A and Fig. 2A). The downregulation was confirmed by western blots (Fig. S2B-C and Fig. 2B-C). Further, the expression of antioxidant genes was also downregulated as was catalase activity both in the absence and presence of oxidative stress (Fig. S2D-E and Fig. 2D-E respectively). ROS levels, as analyzed by the DCFDA label, were found to be significantly upregulated (Pvalue $=0.00)$ in $\mathrm{Sh} P I C H$ cells as compared to HeLa cells transfected with scrambled shRNA both in the absence and presence of $\mathrm{H}_{2} \mathrm{O}_{2}$ (Fig. S2F-G and Fig. 2F-G respectively). PICH downregulation has been reported to increase DNA damage [24]. Increased number of $\gamma \mathrm{H} 2 \mathrm{AX}$ foci positive cells in ShPICH cells as compared to ScrRNA cells were observed both in the absence $(\mathrm{P}=0.01)$ and presence $(\mathrm{P}=8.04 \mathrm{E}-08)$ of $\mathrm{H}_{2} \mathrm{O}_{2}$ (Fig. S2H-I and Fig. 2H-I). Furthermore, the number of $\gamma \mathrm{H} 2 \mathrm{AX}$ foci positive ShPICH cells were more in the treated condition as compared to untreated condition $(\mathrm{P}$-value $=0.006)$ indicating increased DNA damage in the presence of oxidative stress when PICH expression is ablated. The downregulation of NRF2 could be rescued by overexpressing $\mathrm{PICH}$ in 
2J). The expression of antioxidant genes, as well as catalase activity, was also found to be cassette as compared to cells transfected with vector alone (Fig. $2 \mathrm{~K}$ and L; untreated controls are shown in Fig. S2K and L).

The ATPase activity of PICH is required for transcriptional regulation: To

understand whether the ATPase activity of the protein is required for transcriptional to alanine in the full-length PICH [9]. Co-transfection of the plasmid expressing the mutant PICH (PICHK128A) with ShPICH into HeLa cells showed that the expression of Nrf2, as well as antioxidant genes, was not rescued when transfected cells were treated $100 \mu \mathrm{M} \mathrm{H}_{2} \mathrm{O}_{2}$ for 20 min highlighting the importance of ATPase activity of PICH in transcriptional regulation (Fig. 2M and N; untreated controls are shown in Fig. S2M and N). presence of oxidative stress. Further, PICH also regulates the genes encoding for regulation as overexpression of the ATPase dead mutant failed to rescue the downregulation of genes in ShPICH cells.

stress: As the expression of PICH was upregulated on oxidative stress, we asked whether

177 Nrf2 has a role in regulating the expression of this gene on oxidative stress. Nrf2 is a the expression of antioxidant genes [25]. The polymorphic ARE core sequence 5'of genes encoding for antioxidant genes [26,27]. An in silico analysis identified ARE 
sequence was present on the $\mathrm{PICH}$ promoter leading us to hypothesize that $\mathrm{Nrf} 2$ could potentially regulate the expression of this gene. (Supplementary Table 3).

Nrf2 expression was downregulated by transiently transfecting HeLa cells with shRNA against the $3^{\prime}$ UTR of the gene. Downregulation of $N r f 2$ led to reduced expression of $P I C H$ both in the absence $(\mathrm{P}-$ value $=3.56 \mathrm{E}-06)$ and presence $(\mathrm{P}$-value $=1.65 \mathrm{E}-05)$ of oxidative stress (Fig. 3A-F). The expression of PICH in Nrf2 downregulated cells could be rescued by overexpressing $N r f 2$ in the presence of oxidative stress (Fig. 3G and H; heat maps shown in Fig. S3)

From these experimental results, we concluded that in HeLa cells, Nrf2 regulates the expression of $\mathrm{PICH}$ only on oxidative stress.

Thus, PICH regulates Nrf2 both in the absence and presence of oxidative stress while Nrf2 regulates $P I C H$ only in the presence of oxidative stress.

\section{The occupancy of PICH and Nrf2 increases on the promoters of effector genes on}

oxidative stress: To understand the mechanism of transcriptional regulation by $\mathrm{PICH}, \mathrm{ChIP}$ experiments were done to probe the occupancy of PICH, Nrf2, and RNAPII on PICH, Nrf2, SOD1, GPX1 and TXNRD1 promoters in the absence and presence of oxidative stress. On the $P I C H$ promoter, PICH, Nrf2, and RNAPII occupancy increased only on oxidative stress (Fig. 4A; heat map shown in Fig. S4B). This suggests that Nrf2 does regulate the expression of $\mathrm{PICH}$ on oxidative stress. Further, $\mathrm{PICH}$ appears to co-regulate its own transcription.

PICH and Nrf2 were both found to be present on the Nrf2 promoter; their occupancy decreased with oxidative stress as compared to the occupancy in the absence of oxidative stress (Fig. 4B; heat map shown in Fig. S4B). Overall, PICH regulates Nrf2 both in the absence and presence of oxidative stress. RNAPII occupancy, on the other hand, increased 
on the promoter on oxidative stress correlating with increased transcription of $N r f 2$ (Fig. 4B; heat map shown in Fig. S4B).

Finally, PICH, Nrf2, and RNAPII occupancy increased on GPX1, TXNRD1, and SOD1 promoters on oxidative stress, correlating with increased transcription (Fig. 4C-E; heat map shown in Fig. S4B).

In contrast, the occupancy of PICH, Nrf2, and RNAPII did not alter on GAPDH promoter (Fig. 4F; heat map shown in Fig. S4B) indicating that the change in occupancy was specific to the genes involved in oxidative stress response.

Thus, PICH binds to the promoter (ARE) sequences of its target genes and coregulates transcription with $\mathrm{Nrf2}$.

\section{Histone marks associated with transcription activation are enriched on PICH,}

Nrf2, and antioxidant gene promoters on oxidative stress: We hypothesized that the increased transcription of $\mathrm{PICH}, \mathrm{Nrf2}$, and antioxidant genes should be accompanied by an increase in activation histone marks. H3K9ac, H3K4me2, H3K4me3, and H3K27ac modifications are associated with transcription activation [28-30].

Analysis of the ChIP-seq data of these histone marks- H3K9c (GSM733756), H3K4me2 (GSM733734), H3K27ac (GSM733684), and H3K4me3 (GSM733682)- available in the public domain [28] showed that these are present on the promoters of $\mathrm{PICH}, \mathrm{Nrf}$, GPX1, TXNRD1 and SOD1 in untreated HeLa cells (Fig. S4A).

Next, ChIP experiments were done to understand the enrichment of H3K4me3 and H3K27ac on PICH, Nrf2, GPX1, TXNRD1, and SOD1 promoters in the absence and presence of oxidative stress.

H3K4me3 and H3K27ac modifications were enriched on PICH promoter in the treated cells as compared to untreated cells (Fig. 5A). On the Nrf2 promoter, however, enrichment of only $\mathrm{H} 3 \mathrm{~K} 27 \mathrm{ac}$ was observed in the treated cells as compared to the untreated 
cells indicating that only this modification is playing a role in transcriptional regulation of this gene (Fig. 5B). Finally, both H3K4me3 and H3K27ac modifications were found to be enriched on GPX1, TXNRD1, and SOD1 promoters in the presence of oxidative stress, indicating both these modifications are associated with transcriptional activation of these genes (Fig. 5C-E). In contrast, neither of these modifications were enriched on the GAPDH promoter (Fig. 5F).

Thus, from these experiments, it was concluded that both $\mathrm{H} 3 \mathrm{~K} 4 \mathrm{me} 3$ and $\mathrm{H} 3 \mathrm{~K} 27 \mathrm{ac}$ were associated with transcriptional regulation of $\mathrm{PICH}$ and antioxidant genes on oxidative stress. Further, only $\mathrm{H} 3 \mathrm{~K} 27 \mathrm{ac}$ was playing a role in transcriptional activation of the $\mathrm{Nrf} 2$ gene on oxidative stress.

The occupancy of Nrf2, RNAPII, and H3K27ac on the target genes is dependent on

PICH expression: Next, we investigated whether PICH is needed for the recruitment of Nrf2, RNAPII, and H3K27ac to the promoters of the target genes on oxidative stress. ChIP experiments were performed using cells transfected with either scrambled shRNA (ScrRNA) or shRNA against PICH (ShPICH) and treated with $\mathrm{H}_{2} \mathrm{O}_{2}$.

The occupancy of RNAPII and H3K27ac decreased on PICH, Nrf2, GPX1, TXNRD1, and SOD1 promoters in the ShPICH cells as compared to ScrRNA cells on oxidative stress correlating with decreased expression of these genes (Fig. 6A-E). Nrf2 occupancy too decreased on PICH, SOD1, GPX1, and TXNRD1 promoters; however, it increased on its own promoter in ShPICH cells as compared to ScrRNA on oxidative stress (Fig. 6B). In contrast, the occupancy of Nrf2, RNAPII, and H3K27ac did not alter on the GAPDH promoter (Fig. $6 \mathrm{~F})$.

Taken together, we hypothesize that PICH is needed for the recruitment of transcription machinery to the target genes on oxidative stress. 
$\mathrm{PICH}$ is present on the target promoters simultaneously with Nrf2. ChIP-reChIP experiments

confirmed that PICH and Nrf2 are indeed present together on the promoter regions of GPXI, TXNRD1, and SOD1 (Fig. 6G- I).

Co-immunoprecipitation showed that PICH interacted either directly or indirectly with both Nrf2 and H3K27ac (Fig. 6J). This interaction was present both in the absence and presence of oxidative stress. However, the H3K27ac modification appears to increase on treatment with $\mathrm{H}_{2} \mathrm{O}_{2}$. Both anti-PICH antibody and anti-Nrf2 antibody appear to pull down this modification on oxidative stress (Fig. 6J). Immunoprecipitation with anti-Nrf2 antibody also pulled down PICH both in the absence and presence of oxidative stress while it pulled down H3K27ac in the presence of oxidative stress (Fig. 6J). present on the promoters of the target genes. Further, PICH and Nrf2 form a complex in the presence of H3K27ac in HeLa cells.

PICH alters the conformation of DNA in an ATP-dependent manner: Studies have shown that PICH does not reposition nucleosomes [8]. In such a scenario, how does PICH co-regulate transcription? Studies have shown that BRG1, as well as SMARCAL1, can induce conformational changes in DNA [20,31,32]. Therefore, we hypothesized that PICH might be co-regulating transcription by remodeling DNA. 
hydrolyze ATP was analyzed in the presence of ARE sequences as ChIP experiments had shown that the protein is bound to these regions. As maximal ATPase activity was observed in the presence of sIDNA, we hypothesized that the protein most probably was recognizing specific structural elements present in the DNA. Mfold [33] showed that the sequence where PICH occupancy was observed by ChIP can potentially form stem-loop structures while QGRS mapper [34] showed these sequences have a low potential for the formation of Gquadruplexes (Supplementary Table 3). Therefore, these sequences were denatured by heating to $95^{\circ} \mathrm{C}$ and then either slow-cooled at room temperature (facilitates inter-strand annealing) or fast-cooled at $4^{\circ} \mathrm{C}$ (facilitates intra-strand annealing). ATPase assays showed that $\triangle \mathrm{PICH}$ but not $\triangle \mathrm{PICHK} 128 \mathrm{~A}$ was able to hydrolyze ATP in presence of all the sequences irrespective of whether they were slow-cooled (SC) or fast-cooled (FC) (Fig. 7E).

To understand whether the sequence or the structure was the critical parameter in protein-DNA recognition, an oligonucleotide that represented only the ARE sequence of GPX1 promoter (GPX1 ARE) was designed (Supplementary Table 3). Mutations (M1 to M4) were introduced at selected positions (Supplementary Table 3). None of these showed that the amount of ATP hydrolyzed was the same for both GPX1 ARE sequence and GPX1 SC (Fig. 7F). Next, we analyzed which of the residues are important for the interaction by mutation analysis. We found that when $\mathrm{T}$ at the $11^{\text {th }}$ position was mutated to $\mathrm{A}$ as in the case of M4 oligonucleotide, the ATPase activity was abolished suggesting that the protein bind to ARE in a sequence-specific manner (Fig. 7F). dichroism (CD) spectroscopy was employed as studies have shown that different conformers of DNA can be identified by this methodology [35]. CD spectra of the GPX1SC DNA showed a large negative peak at $255 \mathrm{~nm}$ and a small negative peak around $270 \mathrm{~nm}$ in the 
presence of ATP and $\triangle \mathrm{PICH}$ (Fig. 7G). The formation of these peaks was abrogated by the addition of EDTA indicating that the conformational change induced in the DNA by PICH was dependent on ATP hydrolysis (Fig. 7G). To understand whether PICH induced the same conformational change in all DNA molecules, the CD spectra of sIDNA in the absence and presence of ATP and $\triangle \mathrm{PICH}$ were also analyzed. In contrast to GPX1SC DNA, the sIDNA formed two positive peaks at $252 \mathrm{~nm}$ and $265 \mathrm{~nm}$, which was again dependent on the ATPase activity of the protein (Fig. 7H and Fig. S5B). genes by inducing conformational changes in the promoter regions. 
DISCUSSION

Oxidative stress reflects the imbalance between the expression of reactive oxygen

species and the ability of the cell to detoxify or repair the damage through reactive intermediates. The reactive oxygen species cause DNA damage, lipid peroxidation, as well as oxidation of proteins. The cell combats the oxidative stress by producing antioxidants like superoxide dismutase, catalase, and glutathione peroxidase that can directly scavenge the free radicals. The expression of these antioxidant enzymes under transcriptional control wherein Nrf2, a transcription factor, has been shown to play a pivotal role. In addition, studies have shown that the expression of antioxidant genes is also co-regulated by chromatin remodeling mechanisms. KMT2D, a histone methyltransferase that catalyzes monomethylation of H3K4, has been shown to regulate the expression of antioxidant genes in prostate cancer [36].

Studies have also shown that transcriptional activation of $\mathrm{HO}-1$, a gene encoding for homo oxygenase -1, by Nrf2 requires BRG1, an ATP-dependent chromatin remodeling protein [3]. However, there are no reports regarding the role of $\mathrm{PICH}$ in mediating transcriptional coregulation of genes encoding for antioxidants during oxidative stress.

PICH was identified as a Plk1 kinase interacting protein and extensive studies have delineated its role in mitosis $[5,37,38]$. Further, studies have shown that PICH is an ATPdependent translocase that can bind and translocate on double-strand DNA but cannot remodel nucleosomes [8]. Thus, the role of this protein in transcriptional co-regulation has not yet been investigated.

PICH, a transcriptional regulator, manages the response to oxidative stress in HeLa cells

In this paper, the role of $\mathrm{PICH}$ as a transcriptional co-regulator when oxidative stress is generated in HeLa cells has been delineated. PICH regulates the expression of Nrf2 as well as genes encoding for antioxidants in HeLa cells. Downregulation of PICH reduces the 
expression of Nrf2 as well as genes encoding for antioxidants leading to increased oxidative

PICH depleted cells restored the expression of $\mathrm{Nrf} 2$ and antioxidants in the presence of oxidative stress. The transcriptional regulation was dependent on the ATPase activity of

PICH as overexpression of ATPase-dead mutant of PICH in PICH depleted cells failed to restore the expression of the effector genes. Finally, ChIP analysis confirmed that PICH can bind to the promoter regions of Nrf2 and antioxidant genes, thus directly regulating their expression.

The expression of $\mathrm{PICH}$ is regulated by $\mathrm{Nrf} 2$ in the presence of oxidative stress. In silico analysis identified ARE sequence in the promoter regions of $\mathrm{PICH}$ and ChIP experiments confirmed that Nrf2 occupancy increases on the PICH promoter only in the presence of oxidative stress. In contrast, $\mathrm{PICH}$ appears to regulate the expression of $\mathrm{Nrf} 2$ both in the absence and presence of oxidative stress. Thus, PICH provides cellular defense by functioning as an oxidative stress induced response factor that regulates transcription of Nrf2 and antioxidant genes.

Analysis of the available ChIP-seq datasets showed that activating histone marksH3K9ac, H3K4me2, H3K27ac, and H3K4me3- are enriched on PICH, Nrf2, GPX1, TXNRD1, and SOD1 promoters. ChIP experiments confirmed that H3K27ac and H3K4me3 are enriched on the PICH, GPX1, TXNRD1, and SOD1 promoter on oxidative stress while only $\mathrm{H} 3 \mathrm{~K} 27 \mathrm{ac}$ is enriched on the Nrf2 promoter. Thus, on oxidative stress, gene expression is regulated by Nrf2, a transcription factor, in collaboration with epigenetic regulators-PICH and activating histone modifications- leading to an open chromatin architecture and thus, increased transcription. promoters of the responsive genes, suggesting that $\mathrm{PICH}$ is needed for the recruitment of the 
transcription machinery on oxidative stress. However, the order of recruitment cannot be

modifying enzyme along with RNAPII and Nrf2. The second possibility is that Nrf2 recruits

PICH, histone modifying enzymes, and RNAPII. Finally, Nrf2 and PICH are both recruited

by H3K27ac modification. The studies presented here do not allow us to differentiate

between these different mechanisms because PICH depletion leads to downregulation of

Nrf2. Additional experiments need to be performed to understand how these factors are

recruited to the target genes on oxidative stress.

PICH-Nrf2-H3K27ac complex possibly directs transcription output during oxidative

stress

the effector promoters. Co-immunoprecipitation showed that $\mathrm{PICH}$ and $\mathrm{Nrf} 2$ possibly form a complex both in the absence and presence of oxidative stress. Further, in the presence of oxidative stress, they appear to interact with the histone modification H3K27ac. Thus, the interaction between an ATP-dependent chromatin remodeler, a transcription factor, and histone modification might be driving the transcriptional output from effector genes on oxidative stress in HeLa cells.

\section{Mechanism of transcriptional regulation by PICH}

As stated earlier, PICH does not appear to possess ATP-dependent nucleosome remodeling activity [8]. However, it can resolve triplex DNA [8]. BRG1, an ATP-dependent chromatin remodeling protein, is known to induce Z-DNA conformation on the $\mathrm{HO}-1$ of DNA present on the promoter regions in an ATP-dependent manner [20,32]. Therefore, it 
was hypothesized that PICH might also alter the conformation of DNA in an ATP-dependent manner. CD spectroscopy showed that PICH can indeed alter the conformation of the DNA. The conformational change induced in the DNA appears to be dependent on the DNA sequence as sIDNA and GPX1SCform different structures. The conformational change induced in a given DNA sequence is dependent on the ATPase activity of the protein. Different DNA conformers have a varying degree of entanglement on a promoter region to make the transcription process feasible. Z-DNA, for example, is known to be stabilized transiently due to the generation of negative supercoiling by the movement of RNAPII, and thus, coupled to transcription regulation [40]. The CD spectra of the GPX1SC sequence show a large negative peak at $255 \mathrm{~nm}$ and another negative peak at $270 \mathrm{~nm}$. These negative peaks are associated with a form of DNA known as X-DNA [35]. Movement of RNAPII across the DNA template generates positive supercoils this transcription-generated positive supercoiling is used to disrupt and/or eliminate road-block proteins, thus, destabilizing nucleosome structure making the underlying DNA more accessible to RNAPII [41,42]. The X-DNA has been proposed to represent an overwound DNA that can potentially function as a sink for the positive supercoiling [43]. Thus, we can hypothesize that PICH possibly facilitates transcription by inducing an X-DNA structure that can act as an absorbent for positive supercoiling. However, further studies are needed to understand how the conformational change in the ARE sequences induced by PICH in the presence of ATP impacts transcription.

In conclusion, $\mathrm{PICH}$ appears to exert its effect through a combination of i) direct regulation of $N r f 2$ expression; ii) ARE recognition and antioxidant response transcriptional regulation with Nrf2; iii) by interacting with histone mark H3K27ac as a part of active transcriptional machinery; and finally, iv) bringing chromatin conformational changes 
414 facilitating transcription, although the exact order of such events cannot be inferred from the

415 study presented.

416 Oxidative stress is lethal to the cell and hence, the cell has devised mechanisms to

417 alleviate it. PICH appears to be central to this process by regulating the expression of both

418 antioxidant genes and Nrf2, the transcription factor involved in regulating the expression of

419 antioxidant genes, thus expanding the role of this protein beyond mitosis into the realm of

420 transcription regulation.

421 


\section{MATERIALS AND METHODS}

Chemicals: DMEM, fetal bovine serum, antibiotic antimycotic solution, and trypsinEDTA solution were purchased from Himedia (USA). Hoechst 33342 and Trizol were purchased from Sigma-Aldrich (USA). Hydrogen peroxide was purchased from Merck (Germany). RevertAid First Strand cDNA Synthesis Kit and TurboFect transfection Reagents were purchased from Thermo Fisher Scientific (USA). Restriction endonucleases were purchased from New England Biolabs (USA). SYBR Green PCR Master Mix was purchased from Kapa Biosystems (USA). Micro-amp Fast 96-well reaction plates, 0.1ml was purchased from Applied Biosystems (USA). QIAquick gel extraction kit was purchased from Qiagen (USA). $\mathrm{Ni}^{+2}$-NTA Sepharose resin was purchased from Novagen (Germany). Protein-G fast flow bead resin and Immobilon-P PVDF membrane were purchased from Merck-Millipore (USA). X-ray films, developer, and fixer were from Kodak (USA).

Primers: Primers for ChIP, qPCR as well as oligonucleotides used for biophysical studies were synthesized either by Sigma-Aldrich (USA). or by GCC Biotech (India). The sequence of the primers and oligonucleotides used in this study is provided in Supplementary Tables 1-3.

Antibodies: BRG1 (catalog\#Ab70558), Histone H3 (catalog\# Ab1791), RNAPII (Rpb1 CTD catalog\# 2629), Nrf2 (catalog\#Ab62352), PICH (catalog\# Ab88560), H3K27ac (catalog\#4729) antibodies were purchased from Abcam (USA). For western blot, Nrf2 (catalog\# 16396-1-AP) was purchased from Proteintech Group (USA). H3K4me3 (catalog\# C42D8) and IgG (catalog\# 2729) were purchased from CST (USA). For immunocytochemistry, $\gamma \mathrm{H} 2 \mathrm{AX}$ (catalog\# SAB5600038) was purchased from Sigma-Aldrich (USA). The secondary antibody (TRITC conjugated IgG and FITC conjugated IgG) was purchased from Genei, Bangalore, India. 
in HeLa cells using shRNA constructs against the 3' UTR. A short region of 21 bases from

TTG-3'). Similarly, a short region from the $3^{\prime}$ UTR was selected as the sense fragment for

451

452

453

454

455

456

457

458

459

460

461

462

463

464

465

466

467

468

469

470

Nrf2 (5'-

CCGGGCTCCTACTGTGATGTGAAATCTCGAGATTTCACATCACAGTAGGAGCTTT

TTG -3'). These were ligated to the antisense fragment interrupted by a non-related spacer

sequence. The double-stranded oligonucleotide encoding the shRNA was cloned into the pLK0.1 vector between AgeI and EcoRI restriction sites.

Overexpression of $\mathrm{PICH}$ and $\mathrm{Nrf2}$ : The enhanced GFP tagged construct for $\mathrm{PICH}$, pEGFP PICH (Nigg CB62) was a gift from Erich Nigg (Addgene plasmid \# 41163; http://n2t.net/addgene:41163; RRID: Addgene_41163) [5].

pcDNA3-EGFP-C4-Nrf2 was a gift from Yue Xiong (Addgene plasmid \# 21549; http://n2t.net/addgene:21549; RRID: Addgene_21549) [44]

Cell culture and transfection: HeLa cells obtained from NCCS, Pune, India were cultured in DMEM containing 10\% fetal bovine serum and $1 \mathrm{X}$ antibiotic antimycotic solution at $37^{\circ} \mathrm{C}$ and $5 \% \mathrm{CO}_{2}$. For inducing oxidative stress, the cells were treated with $100 \mu \mathrm{M}$ hydrogen peroxide for a specified time.

RNA isolation and qPCR: Total RNA was extracted using the Trizol reagent. 90\% confluent cells in a $35 \mathrm{~mm}$ plate were lysed with $1 \mathrm{ml}$ of the Trizol reagent to give a homogenized lysate. The lysate was transferred to an Eppendorf tube. $200 \mu$ of chloroform was added to each tube per $\mathrm{ml}$ of Trizol reagent, shaken vigorously, and allowed to stand for 10-15 min at room temperature. The samples were centrifuged at 11,000 rpm for $15 \mathrm{~min}$ at $4^{\circ} \mathrm{C}$. The top aqueous layer was transferred to a fresh Eppendorf tube and $0.5 \mathrm{ml}$ of 
isopropanol was added per ml of Trizol reagent, mixed, and allowed to stand at room temperature for $10-15 \mathrm{~min}$. The samples were then centrifuged at $11,000 \mathrm{rpm}$ for $10 \mathrm{~min}$ at $4^{\circ} \mathrm{C}$. The RNA pellet obtained was washed with $70 \%$ ethanol and resuspended in DEPCtreated water. The concentration of the purified RNA was determined using NanoDrop 2000 (Thermo Fisher Scientific, USA) and an equal amount of RNA from various samples was used for preparing cDNA using random hexamer primers according to the manufacturer's protocol. The prepared cDNA was checked for quality by performing a PCR using suitable primers.

Quantitative real-time RT-PCR (qPCR) was performed using the 7500 Fast RealTime PCR system (ABI Biosystems, USA). Gene-specific primers designed for exon-exon junctions were used for qPCR. For each reaction, $10 \mu \mathrm{l}$ of samples were prepared in triplicates and the data obtained was analyzed using Fast7500 software provided by the manufacturer.

Chromatin Immunoprecipitation (ChIP): The cells were cross-linked for 10 min by adding formaldehyde (final concentration 1\%) and later quenched by adding glycine (final concentration $125 \mathrm{mM}$ ) to the media. The cells were then washed thoroughly using ice-cold PBS and scraped into $1 \mathrm{ml}$ buffer containing $150 \mathrm{mM} \mathrm{NaCl}, 0.02 \mathrm{M}$ EDTA, $50 \mathrm{mM}$ Tris-Cl $(\mathrm{pH} 7.5), 0.5 \%(\mathrm{v} / \mathrm{v}) \mathrm{NP}-401 \%(\mathrm{v} / \mathrm{v})$ Triton-X100 and $20 \mathrm{mM} \mathrm{NaF}$. The cells were collected in Eppendorf tubes and pelleted at $12000 \mathrm{~g}$ at $4^{\circ} \mathrm{C}$ for 2 min twice. The pelleted cells were treated with freshly prepared $150 \mu 1$ of sonication buffer1 containing $0.01 \mathrm{M} \mathrm{EDTA} \mathrm{pH} \mathrm{8.0,}$ $50 \mathrm{mM}$ Tris- $\mathrm{Cl}(\mathrm{pH} 8.0)$, and $1 \% \mathrm{SDS}$ for $15 \mathrm{~min}$ at $4^{\circ} \mathrm{C}$ on a rocker. This was followed by addition of $50 \mu \mathrm{l}$ of freshly prepared sonication buffer 2 containing 30 M EDTA $40 \mathrm{mM}$ Tris$\mathrm{Cl}(\mathrm{pH} 8.0) 2 \%(\mathrm{v} / \mathrm{v}) \mathrm{NP}-40,0.04 \%(\mathrm{w} / \mathrm{v}) \mathrm{NaF}$. Sonication was done using a water bath sonicator (40 cycles of $30 \mathrm{sec}$ pulse/ $20 \mathrm{sec}$ rest). The sonicated samples were centrifuged, and the supernatant was used for further analysis. $50 \mu 1$ of the sonicated sample was purified 
496

497

498

499

500

501

502

503

504

505

506

507

508

509

510

511

512

513

514

515

516

517

518

519

and DNA concentration was determined. An equal amount of chromatin $(25 \mu \mathrm{g})$ was taken for performing IP using various antibodies. One sample was kept as Beads alone for negative control. Pre-adsorbed protein A bead resin (pre-adsorbed with $75 \mathrm{ng} / \mu \mathrm{l}$ sonicated salmon sperm DNA and $0.1 \mu \mathrm{g} / \mu \mathrm{l}$ of BSA) and 1.5 to $2 \mu \mathrm{g}$ of the desired antibody was added to each sample and incubated overnight at $4^{\circ} \mathrm{C}$ on a rotator. This was followed by washing the pelleted bead resin two times in IP buffer containing $0.15 \mathrm{M} \mathrm{NaCl}, 0.02 \mathrm{M}$ EDTA (pH 8.0), $50 \mathrm{mM}$ Tris-Cl pH8.0,1\% (v/v) NP-40,0.02\% NaF, $0.50 \%$ sodium deoxycholate and $0.1 \%$ SDS. This was followed by washing three times in wash buffer (0.5 M LiCl, 0.02 M EDTA (pH 8.0), 0.1 mM Tris-Cl (pH 8.0) ,1\% (v/v) NP-40, $0.02 \% \mathrm{NaF}$ and $1 \%$ sodium deoxycholate). The immune complexes were again washed twice in IP buffer and then a final wash was given in TE buffer (0.01 M Tris-Cl (pH 8.0), 0.001 M EDTA). The bound DNA was eluted using $100 \mu \mathrm{l}$ of $10 \%$ (w/v) Chelex® 100 (Bio-Rad, USA) slurry prepared as per the manufacturer's instructions. The eluted DNA was used for qPCR using standardized primers.

Western blotting: Adherent cells in $100 \mathrm{~mm}$ dishes were washed with 1X PBS 3-4 times, scraped with a cell scraper, and collected in $1 \mathrm{ml}$ of $1 \mathrm{X}$ PBS. The cells were pelleted at $2500 \mathrm{rpm}$ at $4^{\circ} \mathrm{C}$. The cell lysate was prepared on ice using $300 \mu \mathrm{l}$ of modified RIPA lysis buffer (50 mM Tris-Cl pH7.5, $150 \mathrm{mM} \mathrm{NaCl,} 2 \mathrm{mM}$ EDTA, $0.5 \%$ sodium deoxycholate, $1 \%$ (v/v) NP-40, 0.1\% sodium dodecyl sulphate, 1\% TritonX-100 and 3 mM PMSF). The samples were sonicated for 3 cycles ( $20 \mathrm{sec}$ on, $40 \mathrm{sec}$ off) using a sonicator. The protein concentration was determined using the Bradford assay. $100 \mu \mathrm{g}$ protein was used to run the SDS-PAGE. Western blotting was done as described in

(https://www.abcam.com/protocols/general-western-blot-protocol\#loading-and-running-thegel). The western blots were quantitated using Image $\mathrm{J}$ software. 

free DMEM (SFM) media for $6 \mathrm{~h}$ before the start of the experiment to reduce the level of serum available in the medium.

At the time of the experiment, $10 \mu \mathrm{M}$ DCFDA was added to the cells in dark and incubated at $37^{\circ} \mathrm{C}$ for $10 \mathrm{~min}$. Subsequently, SFM containing $100 \mu \mathrm{M} \mathrm{H}_{2} \mathrm{O}_{2}$ was added, and the cells were further incubated for $20 \mathrm{~min}$. Fluorescence was recorded for at least 100 cells using a fluorescent microscope (Eclipse Ti-E, Nikon) at the FITC range (495nm).

Co-immunoprecipitation: HeLa cells were grown to $80 \%$ confluency. The cells were collected by trypsinization, and the cell pellet was resuspended in Buffer A (10 mM HEPES, (pH 7.4), $10 \mathrm{mM} \mathrm{KCl,} 0.1 \mathrm{mM}$ EDTA, $0.1 \mathrm{mM}$ EGTA, $1 \mathrm{mM}$ DTT, and $0.5 \mathrm{mM}$ PMSF) and incubated on ice for 15 min. Next, $6 \mu 1$ NP-40 was added, vortexed for $15 \mathrm{sec}$, and the supernatant was collected by centrifuging the samples at $8000 \mathrm{rpm}$ for $1 \mathrm{~min}$. The supernatant was collected and kept on ice. The remaining pellet was re-suspended in $50 \mu 1$ Buffer C (20 mM HEPES, (pH 7.4), 0.4 M NaCl,0.1 mM EDTA,0.1 mM EGTA, 1mM DTT, and $0.5 \mathrm{mM}$ PMSF). The samples were vortexed for $60 \mathrm{sec}$ with $5 \mathrm{~min}$ intervals for the next with the previously collected supernatant. For immunoprecipitation, $600 \mu \mathrm{g}$ of protein and 5$6 \mu \mathrm{g}$ of specific antibody were mixed and incubated for $16 \mathrm{~h}$ at $4^{\circ} \mathrm{C}$. The next day, $50 \mu \mathrm{l}$ preequilibrated protein A bead resin was added and incubated on a rotating wheel for $3 \mathrm{~h}$.

541 Subsequently, the beads were collected by centrifugation at $2500 \mathrm{rpm}$ for $5 \mathrm{~min}$ and washed 542 twice with Buffer A. The samples were boiled with protein loading dye at $95^{\circ} \mathrm{C}$ for 10 min 543 and centrifuged at $12000 \mathrm{rpm}$ for $5 \mathrm{~min}$ at $4^{\circ} \mathrm{C}$. The supernatant was collected in a fresh tube and loaded onto an $8 \%$ SDS-PAGE. Western blotting was done as described in 
(https://www.abcam.com/protocols/general-western-blot-protocol\#loading-and-running-the-

gel). The western blots were quantitated using Image $\mathrm{J}$ software.

confluency. The cells were transfected with either ScrRNA or with the ShPICH construct.

After $36 \mathrm{~h}$, the cells were either left untreated or treated with $100 \mu \mathrm{M} \mathrm{H} \mathrm{H}_{2} \mathrm{O}_{2}$ for $20 \mathrm{~min}$ at

$37^{\circ} \mathrm{C}$. The cells were then washed with PBS and fixed with 1:1 methanol: acetone for $20 \mathrm{~min}$

at $4^{\circ} \mathrm{C}$. Subsequently, the cells were washed with $1 \mathrm{X}$ PBS and permeabilized with $0.5 \%$ of

Triton X-100 in PBS for 20 min at $4^{\circ} \mathrm{C}$. After washing with PBS, blocking was done with

$5 \%$ BSA in PBS for at least $6 \mathrm{~h}$ at $37^{\circ} \mathrm{C}$. Then the cells were incubated with primary

with TRITC- and FITC-conjugated secondary antibody along with Hoechst stain for nuclear

staining for $45 \mathrm{~min}$ at $37^{\circ} \mathrm{C}$. After washing 6 times of 5 minutes each with ice-cold $1 \mathrm{X} \mathrm{PBS}$,

the cells were fixed in $70 \%$ glycerol on a glass slide, sealed, and visualized under Nikon

Eclipse TiE microscope. The images for at least 100 cells were analyzed using NiS v 4.0

software. In all the immunocytochemistry experiments 1:100 dilution of PICH antibody,

Site-directed mutagenesis: All the mutants described in the present study were generated by PCR amplification using specific primers (Supplementary Table 4) and the mutations were confirmed by sequencing.

Protein Purification: E. coli BL21 (DE3) was transformed with the plasmids 
570

571

572

573

574

575

576

577

578

579

580

581

582

583

584

585

586

587

588

589

590

591

592

593

mercaptoethanol, and $0.5 \mathrm{mM}$ PMSF. The cells were incubated at $4^{\circ} \mathrm{C}$ for $1 \mathrm{~h}$ and lysed by sonication (15 sec ON and $45 \mathrm{sec}$ OFF; five cycles). After sonication, the cell debris was removed by centrifugation at $10000 \mathrm{rpm}$ for $45 \mathrm{~min}$ at $4^{\circ} \mathrm{C}$. The supernatant, thus, obtained was loaded onto a $\mathrm{Ni}^{2+}$-NTA column. The column was washed with wash buffer $(50 \mathrm{mM}$ Tris-Cl (pH 8.0), $150 \mathrm{mM} \mathrm{NaCl}, 150 \mathrm{mM} \mathrm{MgCl} 2,10 \mathrm{mM} \beta$-mercaptoethanol, $30 \mathrm{mM}$ imidazole, and $0.5 \mathrm{mM}$ PMSF) and the bound protein was eluted with buffer containing 100 $\mathrm{mM}$ imidazole, $50 \mathrm{mM}$ Tris- $\mathrm{Cl}(\mathrm{pH} 8.0), 5 \mathrm{mM} \mathrm{MgCl} 2,100 \mathrm{mM} \mathrm{NaCl}$, and $5 \mathrm{mM} \beta$ mercaptoethanol. The purified fractions thus obtained were analyzed by $10 \%$ SDS-PAGE. The concentration of the purified protein was determined using the Bradford reagent.

ATPase assay: NADH coupled oxidation assay was used to monitor the ATPase activity of purified PICH. Briefly, $0.2 \mu \mathrm{M}$ of protein was incubated in $1 \mathrm{X}$ REG buffer (125 $\mathrm{mM}$ Tris-acetate ( $\mathrm{pH} 8.0), 30 \mathrm{mM}$ magnesium acetate, $300 \mathrm{mM}$ potassium acetate, $25 \mathrm{mM} \beta$ mercaptoethanol, $6.8 \mathrm{mg} / \mathrm{ml}$ of phosphoenolpyruvate, 50 units of pyruvate kinase, and 50 units of lactate dehydrogenase) along with $20 \mathrm{nM}$ DNA and $2 \mathrm{mM}$ ATP, $0.1 \mathrm{mg} / \mathrm{ml} \mathrm{NADH}$ containing in a $250 \mu \mathrm{l}$ of reaction volume. The reaction was incubated for $15 \mathrm{~min}$ at $30^{\circ} \mathrm{C}$ and the absorbance was measured at $340 \mathrm{~nm}$ using a microplate spectrophotometer (BioTek®Synergy).

The sequences of DNA used in the ATPase assays are given in Supplementary Table 3.

Catalase activity assay: The cell lysate was prepared on ice using $300 \mu 1$ of modified RIPA lysis buffer (50 mM Tris-Cl (pH 7.5), 150 mM NaCl, 2 mM EDTA, 0.5\% sodium deoxycholate, $1 \%$ (v/v) NP-40, 0.5\% sodium dodecyl sulphate, $1 \%$ TritonX-100 and $3 \mathrm{mM}$ PMSF). Subsequently, $0.95 \mathrm{ml}$ of $0.1 \mathrm{M}$ phosphate buffer (pH 7.4), $1.0 \mathrm{ml}$ of freshly prepared $0.05 \mathrm{M}$ hydrogen peroxide, and $100 \mu \mathrm{g}$ supernatant were added in a $3 \mathrm{ml}$ cuvette. 
594

595

596

597

598

599

600

601

602

603

604

605

606

607

608

609

610

611

612

613

614

615

616

617

618

The optical density was read at $240 \mathrm{~nm}$ using Cary $60 \mathrm{UV}-$ Vis spectrophotometer (Agilent

Technologies, USA). The activity was calculated as follows:

Catalase activity (nmoles of $\mathrm{H}_{2} \mathrm{O}_{2}$ consumed $/ \mathrm{min} / \mathrm{mg}$ protein) $=\Delta \mathrm{OD} / \mathrm{min} \mathrm{x}$ volume of assay x $10^{9}$ / MEC x volume of enzyme x mg protein x PL x VCF

Where:

Volume of assay $=3.0 \mathrm{ml} \mathrm{MEC}=39.6 \mathrm{M}^{-1} \mathrm{~cm}^{-1}$

Volume of enzyme $=0.05 \mathrm{ml}$

$\mathrm{VCE}=$ Volume conversion factor $=100$

$\mathrm{PL}=$ path length $=1 \mathrm{~cm}$

Circular dichroism (CD): To investigate the conformational changes in the DNA

molecules, reactions were performed in $1 \mathrm{mM}$ sodium phosphate buffer ( $\mathrm{pH} 7.0) .500 \mathrm{nM}$

DNA was incubated with $1 \mu \mathrm{M}$ PICH, $10 \mathrm{mM} \mathrm{Mg}^{+2}$, and $2 \mathrm{mM}$ ATP. The CD spectra (200

$300 \mathrm{~nm}$ ) were recorded using a Chirascan CD spectrophotometer (Applied Photophysics). To

investigate the role of ATP hydrolysis in the conformational change $50 \mathrm{mM}$ EDTA was used

to inhibit the ATPase activity.

4 scans were measured for each reaction. The buffer and ligand contributions were

subtracted. The spectra, thus, obtained in millidegrees was converted to mean residue

ellipticity by using the formula: $[\theta]=(\mathrm{S} \times \mathrm{mRw}) /(10 \mathrm{cl})$.

$\mathrm{S}$ is the CD signal in millidegrees, $\mathrm{c}$ is the protein concentration in $\mathrm{mg} / \mathrm{ml}, \mathrm{mRw}$ is the mean residue mass and 1 is the path length in centimeters.

Statistical analysis: All qPCR and ChIP experiments are reported as average \pm standard error of mean (SEM) of three independent experiments unless otherwise specified.

The statistical significance ( $\mathrm{p}$-value) was calculated using paired t-test available in Sigma

Plot. The differences were considered significant at $\mathrm{p}<0.05$.

Original blots: The original blots are provided in Supplementary Fig. S6. 


\section{ACKNOWLEDGEMENTS}

620

The authors would like to thank the Central Instrumentation Facility, School of Life

621 Sciences for fluorescence microscope, and Advanced Instrumentation Research Facility,

622 JNU, for the CD spectrophotometer.

\section{FUNDING}

624

R.M. was supported by grants from SERB (EMR/2015/002413 and

625 CRG/2020/000607), India. A.D. was supported by a fellowship from CSIR. D.B. was

626 supported by UGC non-NET fellowship.

\section{CONFLICT OF INTEREST}

The authors declare they have no conflict of interest.

629 


\section{REFERENCES}

1 Hargreaves DC \& Crabtree GR (2011) ATP-dependent chromatin remodeling: genetics, genomics and mechanisms. Cell Res 21, 396-420.

2 Rahman I, Marwick J \& Kirkham P (2004) Redox modulation of chromatin remodeling: impact on histone acetylation and deacetylation, NF-kappaB and pro-inflammatory gene expression. Biochem Pharmacol 68, 1255-1267.

3 Zhang J, Ohta T, Maruyama A, Hosoya T, Nishikawa K, Maher JM, Shibahara S, Itoh K \& Yamamoto M (2006) BRG1 Interacts with Nrf2 To Selectively Mediate HO-1 Induction in Response to Oxidative Stress. Molecular and Cellular Biology 26, 79427952.

4 Moore S, Berger ND, Luijsterburg MS, Piett CG, Stanley FKT, Schräder CU, Fang S, Chan JA, Schriemer DC, Nagel ZD, van Attikum H \& Goodarzi AA (2019) The CHD6 chromatin remodeler is an oxidative DNA damage response factor. Nat Commun $\mathbf{1 0}$, 241.

5 Baumann C, Körner R, Hofmann K \& Nigg EA (2007) PICH, a centromere-associated SNF2 family ATPase, is regulated by Plk1 and required for the spindle checkpoint. Cell 128, 101-114.

6 Eisen JA, Sweder KS \& Hanawalt PC (1995) Evolution of the SNF2 family of proteins: subfamilies with distinct sequences and functions. Nucleic Acids Res 23, 2715-2723.

7 Flaus A, Martin DMA, Barton GJ \& Owen-Hughes T (2006) Identification of multiple distinct Snf2 subfamilies with conserved structural motifs. Nucleic Acids Res 34, 2887-2905.

8 Biebricher A, Hirano S, Enzlin JH, Wiechens N, Streicher WW, Huttner D, Wang LH-C, Nigg EA, Owen-Hughes T, Liu Y, Peterman E, Wuite GJL \& Hickson ID (2013) PICH: a DNA translocase specially adapted for processing anaphase bridge DNA. Mol Cell 51, 691-701.

9 Nielsen CF, Huttner D, Bizard AH, Hirano S, Li T-N, Palmai-Pallag T, Bjerregaard VA, Liu Y, Nigg EA, Wang LH-C \& Hickson ID (2015) PICH promotes sister chromatid disjunction and co-operates with topoisomerase II in mitosis. Nat Commun 6, 8962.

10 Liu J, Sun J, Zhang Q \& Zeng Z (2018) shRNA knockdown of DNA helicase ERCC6L expression inhibits human breast cancer growth. Mol Med Rep 18, 3490-3496.

11 Pu S-Y, Yu Q, Wu H, Jiang J-J, Chen X-Q, He Y-H \& Kong Q-P (2017) ERCC6L, a DNA helicase, is involved in cell proliferation and associated with survival and progress in breast and kidney cancers. Oncotarget 8, 42116-42124.

12 Pitchai GP, Kaulich M, Bizard AH, Mesa P, Yao Q, Sarlos K, Streicher WW, Nigg EA, Montoya G \& Hickson ID (2017) A novel TPR-BEN domain interaction mediates PICH-BEND3 association. Nucleic Acids Res 45, 11413-11424.

13 Pitchai GP, Hickson ID, Streicher W, Montoya G \& Mesa P (2016) Characterization of the NTPR and BD1 interacting domains of the human PICH-BEND3 complex. Acta Crystallogr F Struct Biol Commun 72, 646-651.

14 Chan JY, Han XL \& Kan YW (1993) Isolation of cDNA encoding the human NF-E2 protein. Proc Natl Acad Sci USA 90, 11366-11370.

15 McMahon M, Itoh K, Yamamoto M, Chanas SA, Henderson CJ, McLellan LI, Wolf CR, Cavin C \& Hayes JD (2001) The Cap'n'Collar basic leucine zipper transcription factor Nrf2 (NF-E2 p45-related factor 2) controls both constitutive and inducible expression of intestinal detoxification and glutathione biosynthetic enzymes. Cancer Res 61, 3299-3307.

16 Alam J, Stewart D, Touchard C, Boinapally S, Choi AM \& Cook JL (1999) Nrf2, a Cap'n'Collar transcription factor, regulates induction of the heme oxygenase-1 gene. J Biol Chem 274, 26071-26078. 
17 Tkachev VO, Menshchikova EB \& Zenkov NK (2011) Mechanism of the Nrf2/Keap1/ARE signaling system. Biochemistry Mosc 76, 407-422.

18 Villeneuve NF, Lau A \& Zhang DD (2010) Regulation of the Nrf2-Keap1 antioxidant response by the ubiquitin proteasome system: an insight into cullin-ring ubiquitin ligases. Antioxid Redox Signal 13, 1699-1712.

19 Ma Q (2013) Role of nrf2 in oxidative stress and toxicity. Annu Rev Pharmacol Toxicol 53, 401-426.

20 Haokip DT, Goel I, Arya V, Sharma T, Kumari R, Priya R, Singh M \& Muthuswami R (2016) Transcriptional Regulation of ATP-Dependent Chromatin Remodeling Factors: SMARCAL1 and BRG1 Mutually Co-Regulate Each Other. Sci Rep 6, 20532.

21 Moon SJ, Dong W, Stephanopoulos GN \& Sikes HD (2020) Oxidative pentose phosphate pathway and glucose anaplerosis support maintenance of mitochondrial NADPH pool under mitochondrial oxidative stress. Bioeng Transl Med 5, e10184.

22 Nakamura J, Purvis ER \& Swenberg JA (2003) Micromolar concentrations of hydrogen peroxide induce oxidative DNA lesions more efficiently than millimolar concentrations in mammalian cells. Nucleic Acids Res 31, 1790-1795.

23 Song S, Nguyen V, Schrank T, Mulvaney K, Walter V, Wei D, Orvis T, Desai N, Zhang J, Hayes DN, Zheng Y, Major MB \& Weissman BE (2020) Loss of SWI/SNF Chromatin Remodeling Alters NRF2 Signaling in Non-Small Cell Lung Carcinoma. Mol Cancer Res 18, 1777-1788.

24 Albers E, Sbroggiò M, Pladevall-Morera D, Bizard AH, Avram A, Gonzalez P, MartinGonzalez J, Hickson ID \& Lopez-Contreras AJ (2018) Loss of PICH Results in Chromosomal Instability, p53 Activation, and Embryonic Lethality. Cell Rep 24, 3274-3284.

25 He F, Ru X \& Wen T (2020) NRF2, a Transcription Factor for Stress Response and Beyond. Int J Mol Sci 21.

26 Wang X, Tomso DJ, Chorley BN, Cho H-Y, Cheung VG, Kleeberger SR \& Bell DA (2007) Identification of polymorphic antioxidant response elements in the human genome. Hum Mol Genet 16, 1188-1200.

27 Wasserman WW \& Fahl WE (1997) Functional antioxidant responsive elements. Proc Natl Acad Sci U S A 94, 5361-5366.

28 Ernst J, Kheradpour P, Mikkelsen TS, Shoresh N, Ward LD, Epstein CB, Zhang X, Wang L, Issner R, Coyne M, Ku M, Durham T, Kellis M \& Bernstein BE (2011) Mapping and analysis of chromatin state dynamics in nine human cell types. Nature 473, 4349.

29 Kimura H (2013) Histone modifications for human epigenome analysis. J Hum Genet 58, 439-445.

30 Sharifi-Zarchi A, Gerovska D, Adachi K, Totonchi M, Pezeshk H, Taft RJ, Schöler HR, Chitsaz H, Sadeghi M, Baharvand H \& Araúzo-Bravo MJ (2017) DNA methylation regulates discrimination of enhancers from promoters through a $\mathrm{H} 3 \mathrm{~K} 4 \mathrm{me} 1-\mathrm{H} 3 \mathrm{~K} 4 \mathrm{me} 3$ seesaw mechanism. BMC Genomics 18, 964.

31 Liu H, Mulholland N, Fu H \& Zhao K (2006) Cooperative Activity of BRG1 and Z-DNA Formation in Chromatin Remodeling. Molecular and Cellular Biology 26, 25502559.

32 Sharma T, Bansal R, Haokip DT, Goel I \& Muthuswami R (2015) SMARCAL1 Negatively Regulates C-Myc Transcription By Altering The Conformation Of The Promoter Region. Sci Rep 5, 17910.

33 Zuker M (2003) Mfold web server for nucleic acid folding and hybridization prediction. Nucleic Acids Res 31, 3406-3415. 
34 Kikin O, D'Antonio L \& Bagga PS (2006) QGRS Mapper: a web-based server for predicting G-quadruplexes in nucleotide sequences. Nucleic Acids Research 34, W676-W682.

35 Kypr J, Kejnovska I, Renciuk D \& Vorlickova M (2009) Circular dichroism and conformational polymorphism of DNA. Nucleic Acids Research 37, 1713-1725.

36 Lv S, Wen H, Shan X, Li J, Wu Y, Yu X, Huang W \& Wei Q (2019) Loss of KMT2D induces prostate cancer ROS-mediated DNA damage by suppressing the enhancer activity and DNA binding of antioxidant transcription factor FOXO3. Epigenetics 14, 1194-1208.

37 Hübner NC, Wang LH-C, Kaulich M, Descombes P, Poser I \& Nigg EA (2010) Reexamination of siRNA specificity questions role of PICH and Tao1 in the spindle checkpoint and identifies Mad2 as a sensitive target for small RNAs. Chromosoma 119, 149-165.

38 Kurasawa Y \& Yu-Lee L (2010) PICH and cotargeted Plk1 coordinately maintain prometaphase chromosome arm architecture. Mol Biol Cell 21, 1188-1199.

39 Maruyama A, Mimura J, Harada N \& Itoh K (2013) Nrf2 activation is associated with ZDNA formation in the human HO-1 promoter. Nucleic Acids Res 41, 5223-5234.

40 Rich A \& Zhang S (2003) Z-DNA: the long road to biological function. Nat Rev Genet 4, 566-572.

41 Clark DJ \& Felsenfeld G (1991) Formation of nucleosomes on positively supercoiled DNA. EMBO J 10, 387-395.

42 Ma J \& Wang MD (2016) DNA supercoiling during transcription. Biophys Rev 8, 75-87.

43 Kypr J, Chládková J, Arnold L, Sági J, Szemzö A \& Vorlícková M (1996) The unusual Xform DNA in oligodeoxynucleotides: dependence of stability on the base sequence and length. J Biomol Struct Dyn 13, 999-1006.

44 Furukawa M \& Xiong Y (2005) BTB protein Keap1 targets antioxidant transcription factor Nrf2 for ubiquitination by the Cullin 3-Roc1 ligase. Mol Cell Biol 25, 162-171.

45 Truax AD \& Greer SF (2012) ChIP and Re-ChIP Assays: Investigating Interactions Between Regulatory Proteins, Histone Modifications, and the DNA Sequences to Which They Bind. In Transcriptional Regulation (Vancura A, ed), pp. 175-188. Springer New York, New York, NY. 
FIGURE LEGENDS

764

765

766

767

768

769

770

771

772

773

Figure 1. PICH expression is upregulated when cells are exposed to oxidative stress.

(A). Expression of $P I C H$ was analyzed at indicated time points in HeLa cells after treatment with $100 \mu \mathrm{M} \mathrm{H}_{2} \mathrm{O}_{2}$ by qPCR. (B). Expression of PICH was examined by western blot. H3 was used as an internal control. (C). Quantitation of the western blot using Image $\mathrm{J}$ software. (D). Cellular ROS was analyzed using DCFDA in HeLa cells in the absence and presence of $\mathrm{H}_{2} \mathrm{O}_{2}$. (E). Fluorescent intensity was quantitated using the software provided by TiE, Nikon Microscope. (F). $\gamma \mathrm{H} 2 \mathrm{AX}$ foci formation was visualized absence and presence of $\mathrm{H}_{2} \mathrm{O}_{2}$ in HeLa cells using confocal microscope. (G). Quantitation of the $\gamma \mathrm{H} 2 \mathrm{AX}$ positive cells. $(\mathrm{H})$. Expression of PICH, Nrf2, BRG1, and SMARCAL1 were quantitated using qPCR. (I). Expression of PICH, Nrf2, BRG1, and SMARCAL1 was analyzed by western blot. (J). Quantitation of the western blot using ImageJ software. (K). Expression of antioxidant genes CAT, GPX1, GSR, TXNRD1, and SOD1 was analyzed by qPCR. (L). Catalase activity ( $\mu \mathrm{mol} / \mathrm{min})$ was quantitated in untreated and treated $\left(100 \mathrm{mM} \mathrm{H}_{2} \mathrm{O}_{2} ; 20 \mathrm{~min}\right)$ HeLa cells. GAPDH was used as the internal control in all the qPCR experiments. The qPCR experiments are presented as average \pm SEM of three independent experiments. The star indicates p-value is $<0.05$.

The western blots are presented as average \pm SEM of two individual experiments. The intensities of the proteins were normalized with respect to $\mathrm{H} 3$ and are represented as Relative Intensity in the y-axis.

\section{Figure 2. PICH regulates the expression of $\mathrm{Nrf} 2$ in $\mathrm{HeLa}$ cells in the absence and} presence of oxidative stress. (A). Expression of $\mathrm{PICH}$ and $\mathrm{Nrf2}$ in HeLa cells transfected with either ScrRNA or with ShPICH plasmid in HeLa cells after treatment with $100 \mu \mathrm{M}$ $\mathrm{H}_{2} \mathrm{O}_{2}$ for 20 min. (B). Expression of PICH and $\mathrm{Nrf} 2$ in treated $\left(100 \mu \mathrm{M} \mathrm{H}_{2} \mathrm{O}_{2} ; 20 \mathrm{~min}\right) \mathrm{HeLa}$ cells transfected with either ScrRNA or with ShPICH was analyzed by western blot. (C). 
Quantitation of the western blots. (D). Expression of antioxidant genes CAT, GPX1, GSR, TXNRD1, and SOD1 were quantitated by qPCR in treated $\left(100 \mu \mathrm{M} \mathrm{H}_{2} \mathrm{O}_{2} ; 20\right.$ min) HeLa cells transfected either with ScrRNA or with ShPICH. (E). Catalase activity ( $\mu \mathrm{mol} / \mathrm{min})$ was quantitated in treated $\left(100 \mu \mathrm{M} \mathrm{H}_{2} \mathrm{O}_{2} ; 20 \mathrm{~min}\right) \mathrm{HeLa}$ cells transfected either with ScrRNA or with ShPICH. (F). Cellular ROS was analyzed using DCFDA in treated HeLa cells transfected either with ScrRNA or with ShPICH. (G). Fluorescent intensity was quantitated using the software provided by TiE, Nikon Microscope. $(\mathrm{H}), \gamma \mathrm{H} 2 \mathrm{AX}$ foci formation was visualized in treated HeLa cells transfected either ScrRNA or with ShPICH using confocal microscope. (I). Quantitation of the $\gamma \mathrm{H} 2 \mathrm{AX}$ positive cells. (J). Transcript levels of PICH and Nrf2 were quantitated by qPCR in treated $\left(100 \mu \mathrm{M} \mathrm{H}_{2} \mathrm{O}_{2} ; 20 \mathrm{~min}\right) \mathrm{HeLa}$ cells transfected with ScrRNA and empty vector or with the ShPICH and PICH overexpression construct. (K). Expression of antioxidant genes CAT, GPX1, GSR, TXNRD1, and SOD1 were quantitated in treated $\left(100 \mu \mathrm{M} \mathrm{H}_{2} \mathrm{O}_{2} ; 20\right.$ min) HeLa cells transfected with ScrRNA and empty vector or with the ShPICH and $P I C H$ overexpression construct. (L). Catalase activity ( $\mu \mathrm{mol} / \mathrm{min})$ was estimated in treated $\left(100 \mathrm{mM} \mathrm{H}_{2} \mathrm{O}_{2} ; 20 \mathrm{~min}\right) \mathrm{HeLa}$ cells transfected with ScrRNA and empty vector or with the ShPICH and PICH overexpression construct. (M). Transcript levels of $P I C H$ and $N r f 2$ were quantitated by qPCR in treated $\left(100 \mu \mathrm{M} \mathrm{H}_{2} \mathrm{O}_{2} ; 20\right.$ min) HeLa cells transfected with ScrRNA and empty vector or with the ShPICH and PICH K128A overexpression construct. (N). Expression of antioxidant genes CAT, GPX1, GSR, TXNRD1, and SOD1 were quantitated in treated (100 $\mu \mathrm{M} \mathrm{H}_{2} \mathrm{O}_{2} ; 20$ min) HeLa cells transfected with ScrRNA and empty vector or with the ShPICH and PICH K128A overexpression construct.

GAPDH was used as the internal control in the qPCR experiments. The qPCR experiments are presented as average \pm SEM of three independent experiments. The western blots are presented as average \pm SEM of three independent experiments. The intensities were 
quantitated using Image J software. The intensities of the proteins were normalized with respect to $\mathrm{H} 3$ and are represented as Relative Intensity in the y-axis.

The knockdown efficiency of $\mathrm{PICH}$ was $50-60 \%$ in all the experiments performed.

oxidative stress. (A). Expression of $\mathrm{PICH}$ and $\mathrm{Nrf} 2$ in untreated HeLa cells transfected either with ScrRNA or with ShNrf2 construct. (B). Expression of PICH and Nrf2 was analyzed by western blot in untreated HeLa cells transfected either with ScrRNA or with the ShNrf2 construct. (C). Quantitation of the western blots. (D). Expression of PICH and Nrf2 in treated $\left(100 \mu \mathrm{M} \mathrm{H}_{2} \mathrm{O}_{2} ; 20 \mathrm{~min}\right) \mathrm{HeLa}$ cells transfected either with ScrRNA or with ShNrf2

Quantitation of the western blots. (G). Transcript levels of PICH and Nrf2 were estimated by qPCR in untreated HeLa cells transfected either with ScrRNA and empty vector or with ShNrf2 construct along with Nrf2 overexpression plasmid constructs. (H). Transcript levels of PICH and $\mathrm{Nrf} 2$ were estimated by qPCR in treated $\left(100 \mu \mathrm{M} \mathrm{H}_{2} \mathrm{O}_{2} ; 20 \mathrm{~min}\right) \mathrm{HeLa}$ cells transfected either with ScrRNA and empty vector or with ShNrf2 construct along with Nrf2 overexpression plasmid constructs.

GAPDH was used as the internal control in the qPCR experiments. The qPCR experiments are presented as average \pm SEM of three independent experiments. The western blots are presented as average \pm SEM of three independent experiments. The intensities were respect to $\mathrm{H} 3$ and are represented as Relative Intensity in the $\mathrm{y}$-axis. 
Nrf2 promoter; (C). GPX1promoter; (D). TXNRD1 promoter; (E). SOD1 promoter; and (F). GAPDH promoter was analyzed by ChIP in untreated and treated $\left(100 \mu \mathrm{M} \mathrm{H}_{2} \mathrm{O}_{2}\right.$ for $\left.20 \mathrm{~min}\right)$ HeLa cells.

In these experiments, primers were made to probe a region $-300 \mathrm{bp}$ upstream and $+200 \mathrm{bp}$ downstream of the transcription start site (TSS). GAPDH promoter was used as the negative control. The ChIP data are presented as average \pm SEM of three independent experiments. Star indicates significance at $\mathrm{p}$-value is $<0.05$.

Figure 5. Histone marks associated with transcription activation are enriched on PICH, Nrf2, and antioxidant gene promoters on oxidative stress. The fold enrichment of H3K4me3 and H3K27ac as a ratio of $\mathrm{H} 3$ was determined using ChIP on the (A). PICH promoter; (B). Nrf2 promoter; (C). GPX1 promoter; (D). TXNRD1 promoter; (E). SOD1 promoter; and (F) GAPDH promoter in untreated and treated (100 $\mu \mathrm{M} \mathrm{H}_{2} \mathrm{O}_{2} ; 20$ min) HeLa cells.

In these experiments, primers were made to probe a region -300 bp upstream and $+200 \mathrm{bp}$ downstream of the transcription start site (TSS). GAPDH promoter was used as the negative control. The ChIP data are presented as average \pm SEM of three independent experiments.

Star indicates significance at $\mathrm{p}$-value is $<0.05$.

\section{Figure 6. The occupancy of Nrf2, RNAPII, and H3K27ac on the target genes is}

dependent on PICH expression. Occupancy of Nrf2, RNAPII, and H3K27ac was assessed using ChIP in HeLa cells transfected either with ScrRNA or ShPICH after treatment with 100 $\mu \mathrm{M} \mathrm{H}_{2} \mathrm{O}_{2}$ for 20 min on (A). PICH promoter; (B). Nrf2 promoter; (C). GPX1 promoter; (D). TXNRD1 promoter; (E). SOD1 promoter; and (F). GAPDH promoter. Simultaneous occupancy of PICH and Nrf2 was assessed in untreated and treated HeLa cells using ChIP reChIP on (G). GPX1 promoter; (H). TXNRD1 promoter and (I). SOD1 promoter. (J). 
Interaction between PICH, Nrf2, and $\mathrm{H} 3 \mathrm{~K} 27 \mathrm{ac}$ was probed in untreated and treated $(100 \mu \mathrm{M}$ control.

In these experiments, primers were made to probe a region $-300 \mathrm{bp}$ upstream and $+200 \mathrm{bp}$ downstream of the transcription start site (TSS). The ChIP data are presented as average \pm SEM of three independent experiments. Star indicates significance at $p$-value is $<0.05$. In the ChIP-reChIP experiments, primers were made to probe a region -300 bp upstream and +200 bp downstream of the transcription start site (TSS). The ChIP-reChIP data for SOD1, GPX1, and TXNRD1 promoters are presented as average \pm SEM of two independent experiments.

871 Star indicates significance at $\mathrm{p}$-value is $<0.05$.

Figure 7. PICH alters the conformation of DNA in an ATP-dependent manner. (A). to alanine. (B). Coomassie Blue stained gel showing purified recombinant $\triangle \mathrm{PICH}$ protein effectors. (D). ATPase activity of the $\triangle \mathrm{PICHK} 128 \mathrm{~A}$ and $\triangle \mathrm{PICH}$ was measured in the presence of different DNA effectors. (E). ATPase activity $\triangle \mathrm{PICH}$ was measured in the presence of DNA sequences where PICH binding was observed by ChIP. (F). ATPase assay of $\triangle \mathrm{PICH}$ protein was measured in the presence of GPX1ARE wild type and mutated sequences. (G). CD spectra of slow-cooled GPX1SC DNA in the absence and presence of $\triangle \mathrm{PICH}$ and ATP. (H). Comparison of the CD spectra of sIDNA and GPX1SC in the absence and presence of $\triangle \mathrm{PICH}$ and ATP. included. 


\section{A $\quad$ Figure 1}

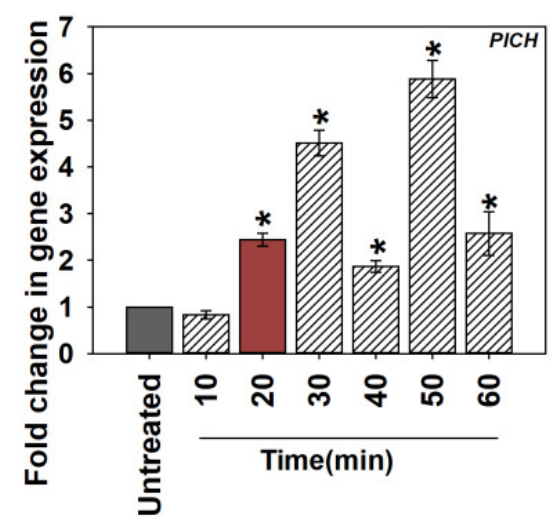

E

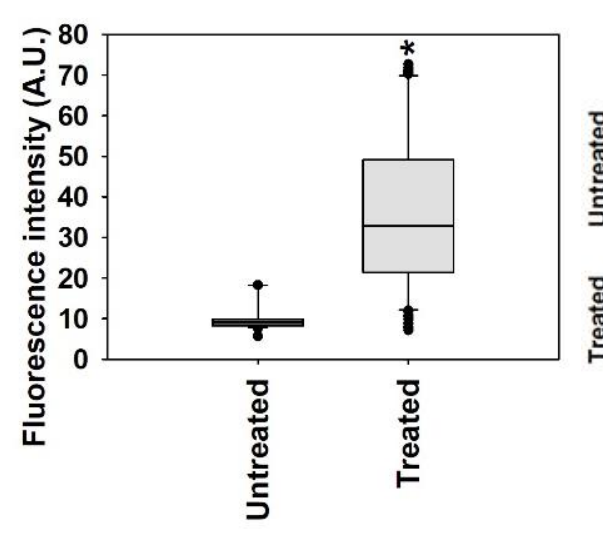

I

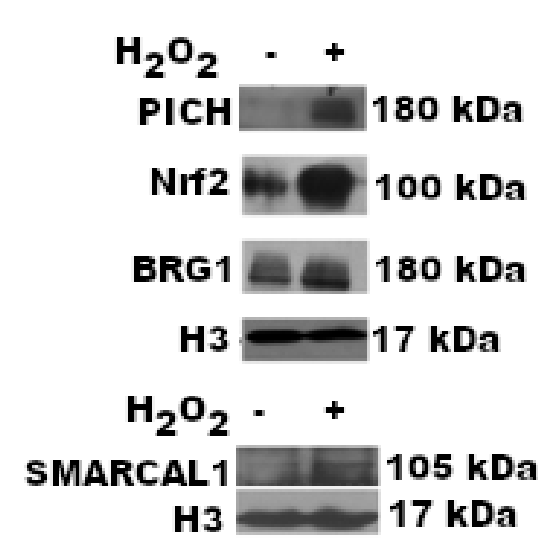

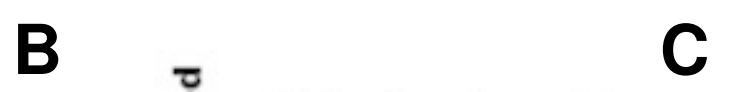

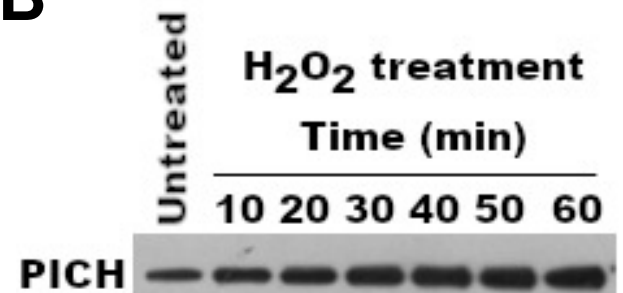

H3

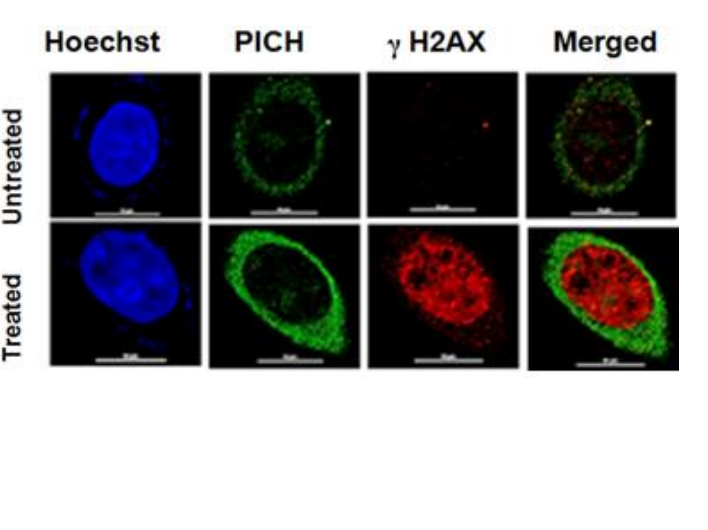

J

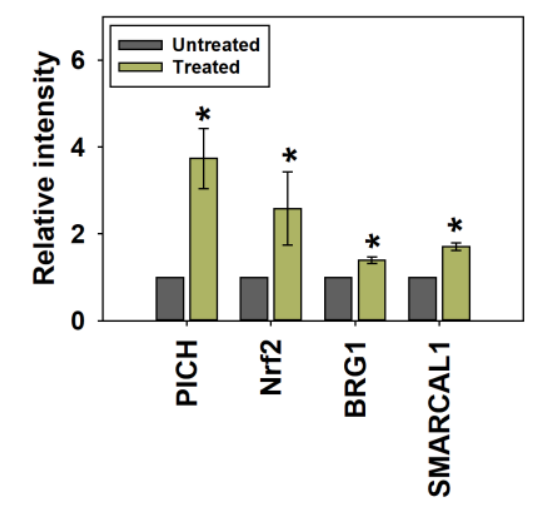

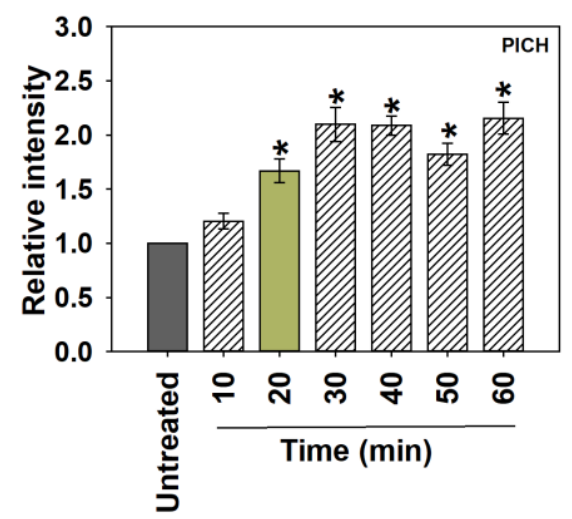

G

D

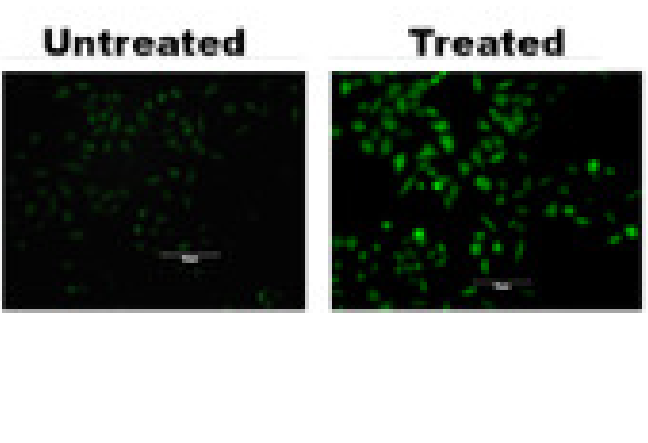

H
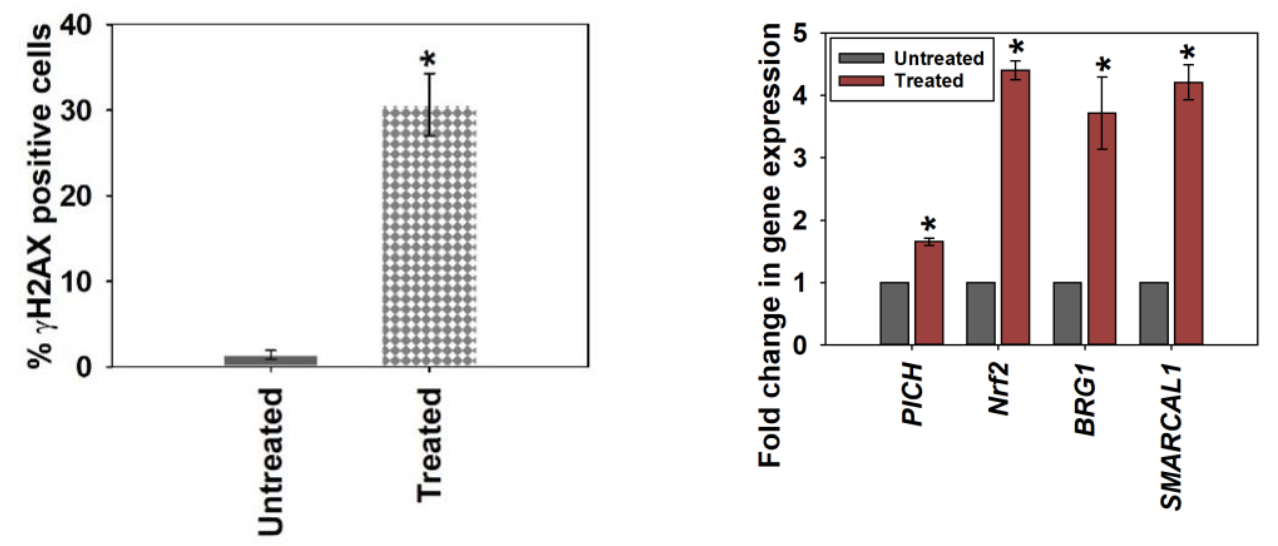

K

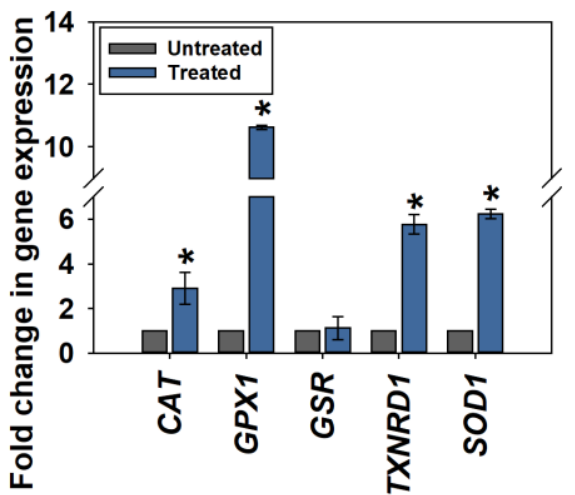

$\mathbf{L}$

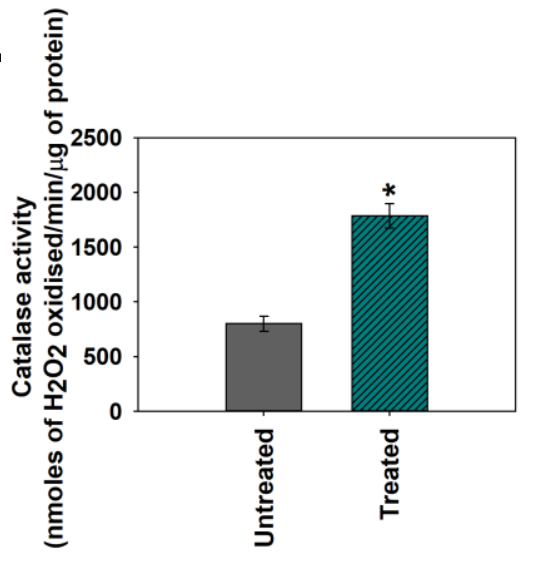




\section{Figure 3}
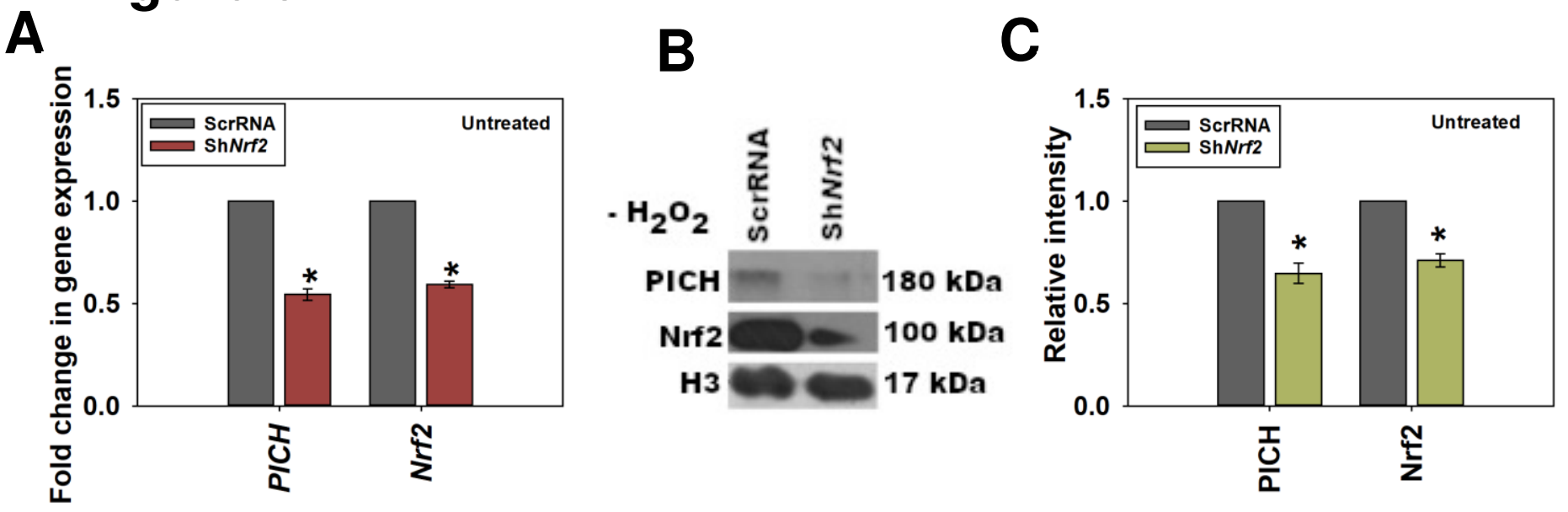

E

F
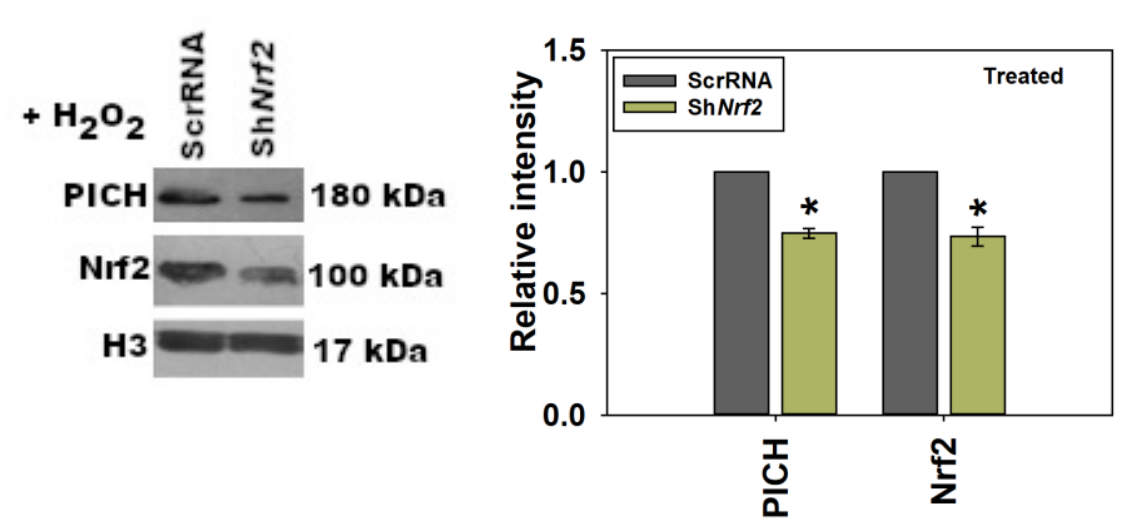

G

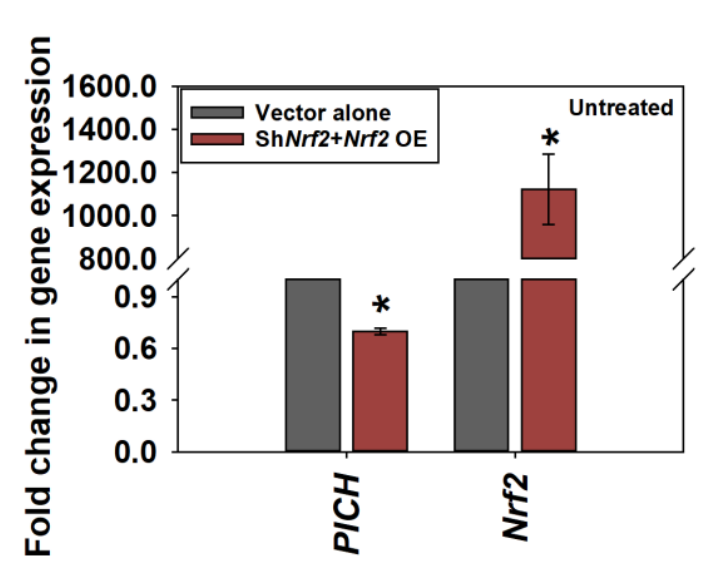

D

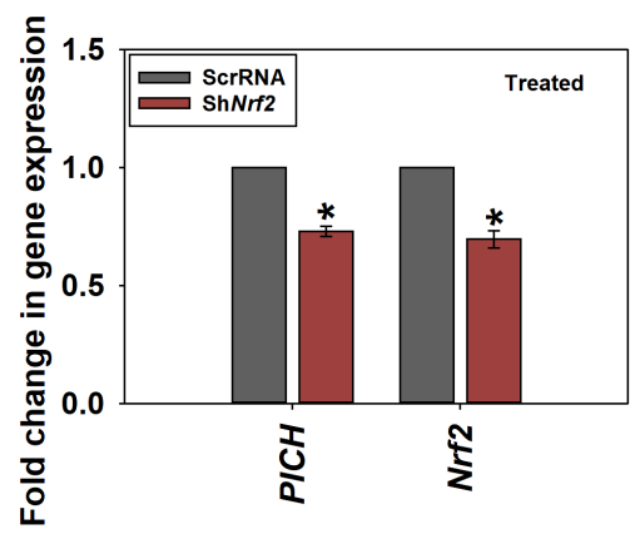

H

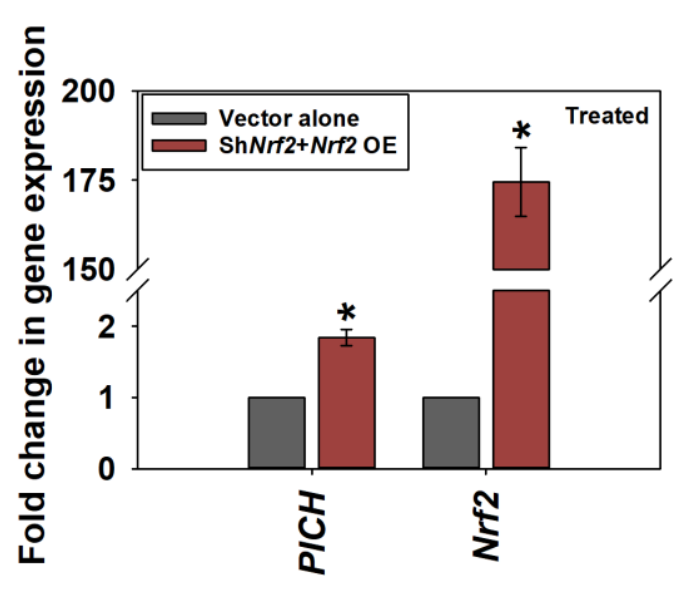


Figure 4

A

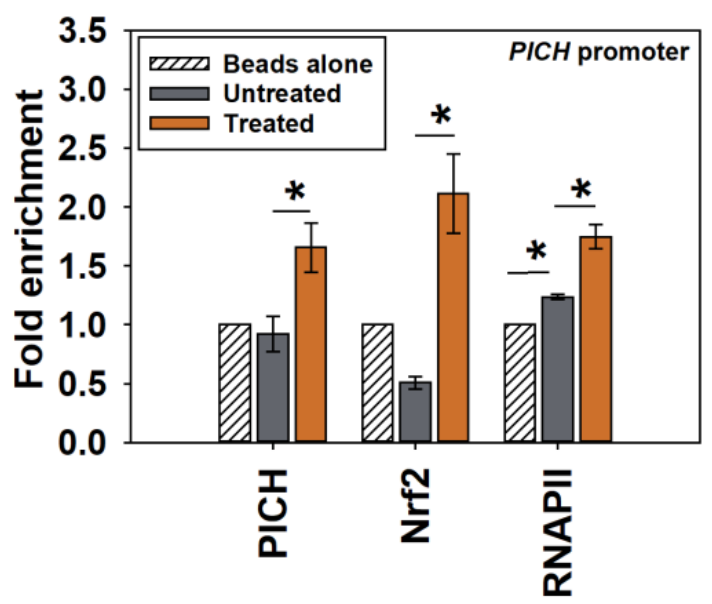

D

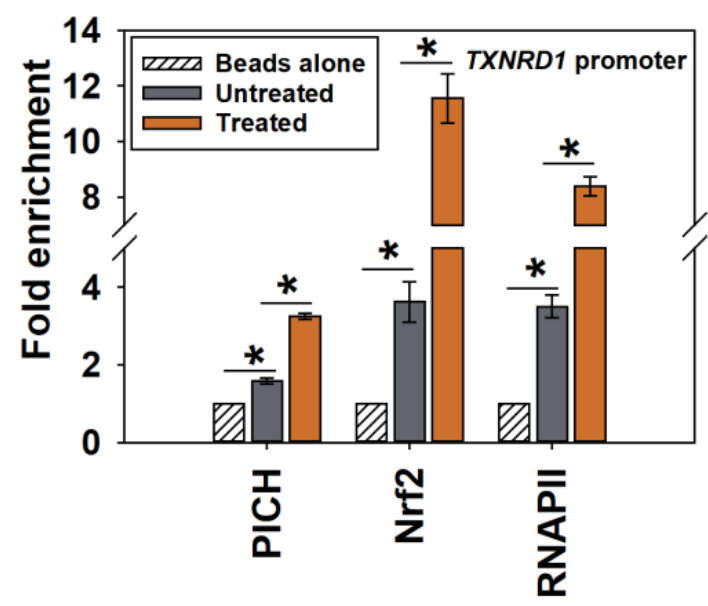

B

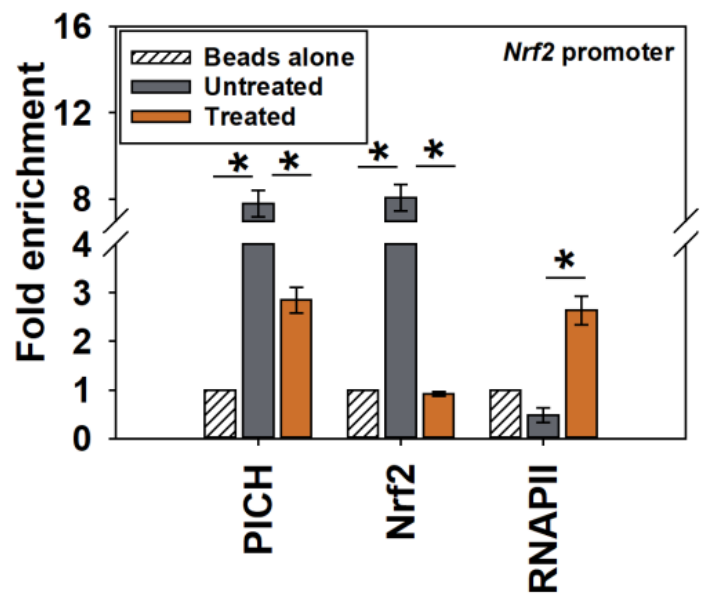

E

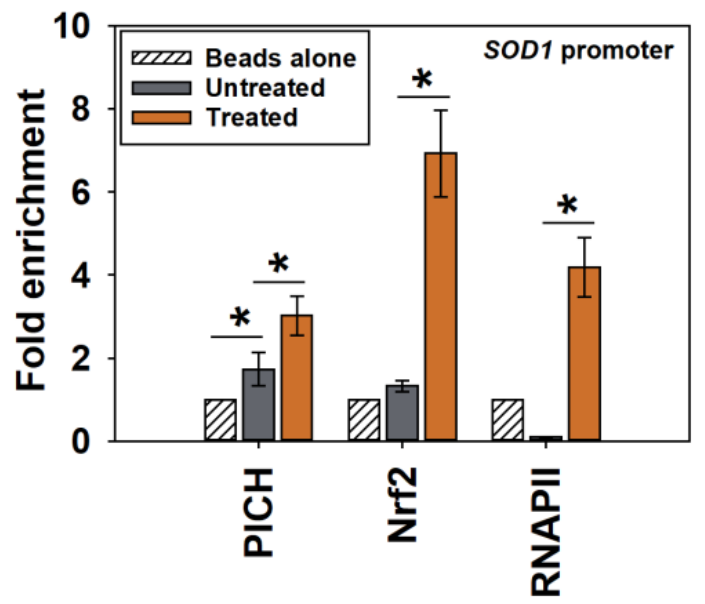

C

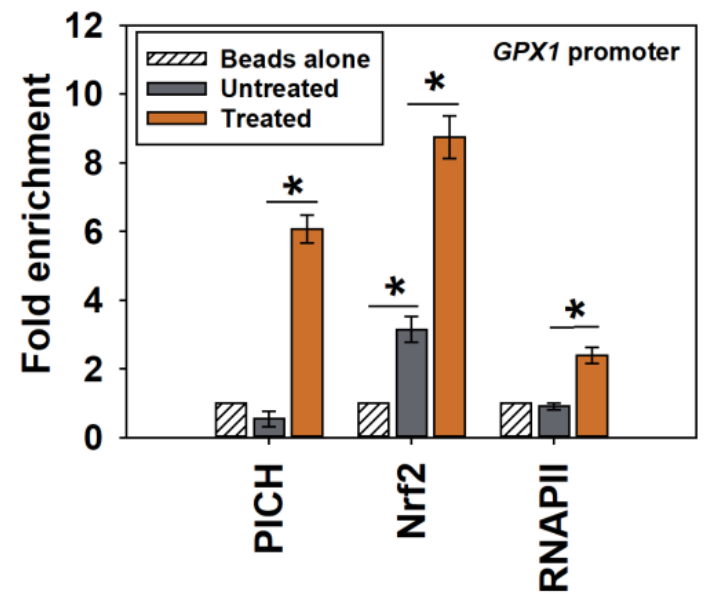

F

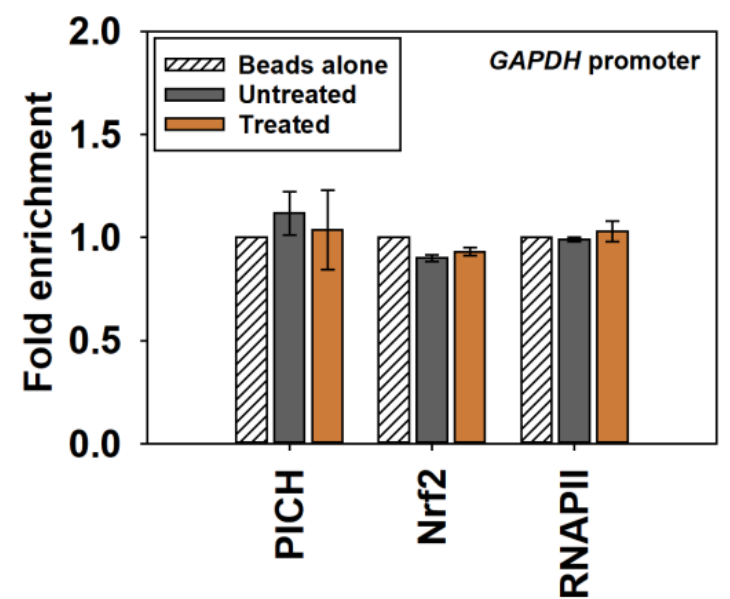


Figure 5

A

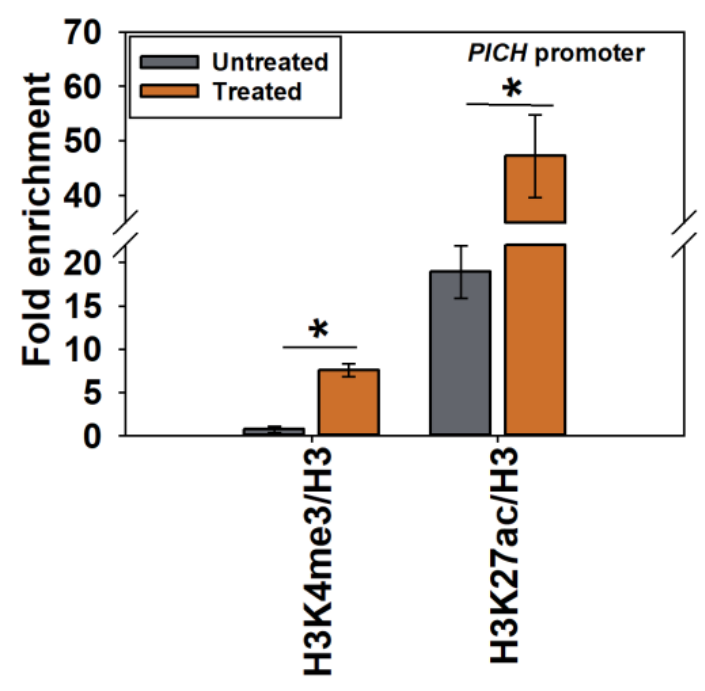

D

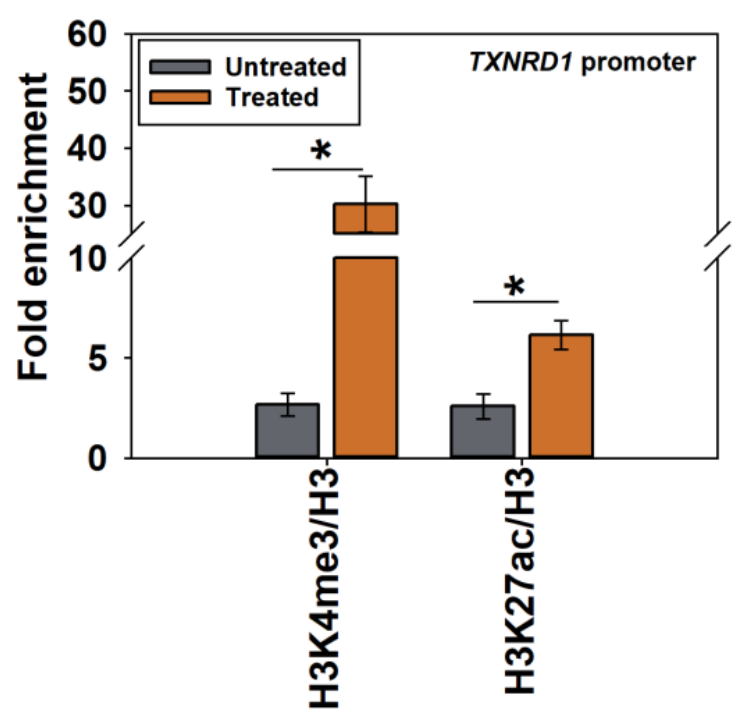

B

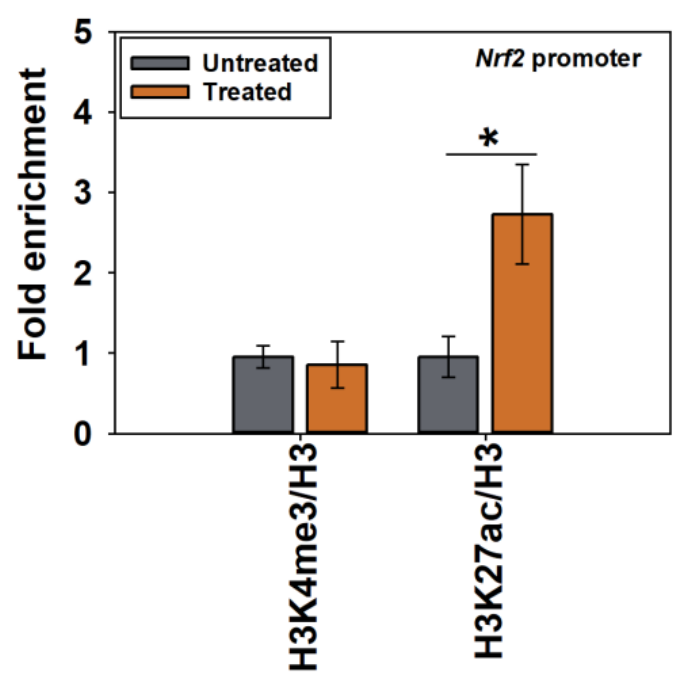

E

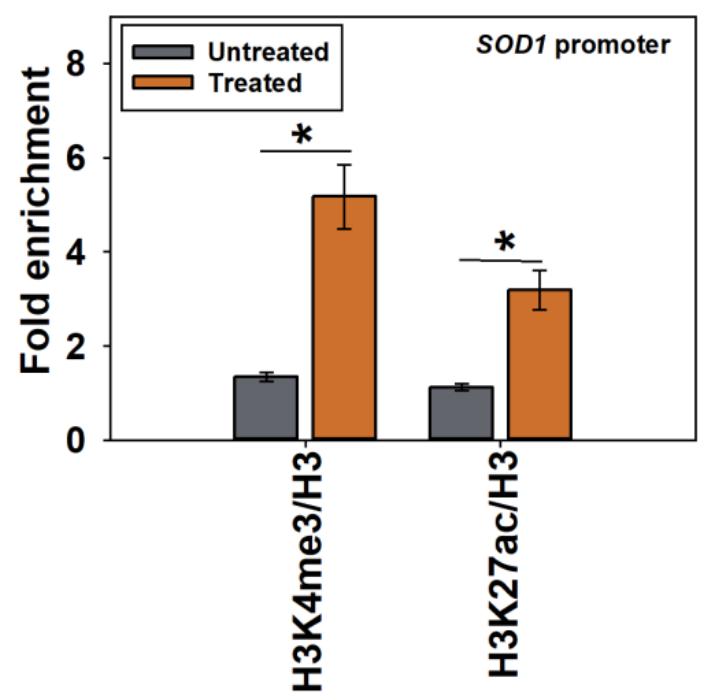

C

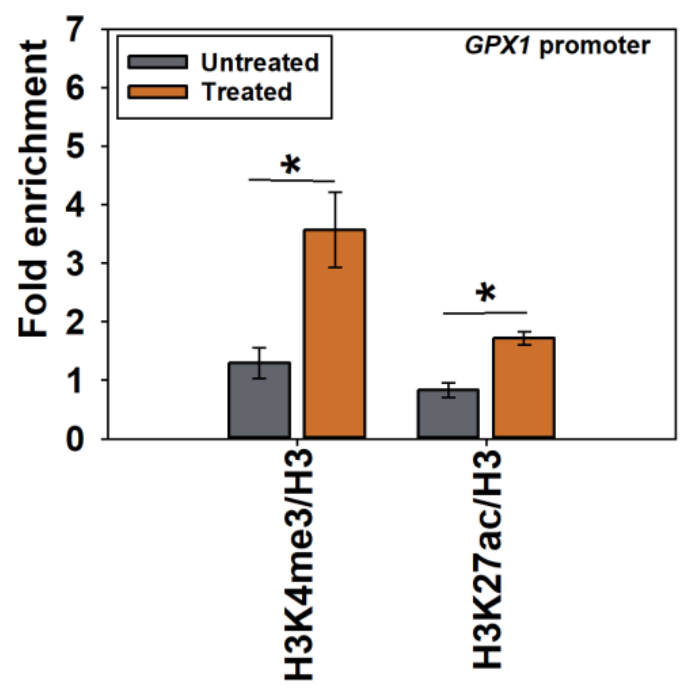

F

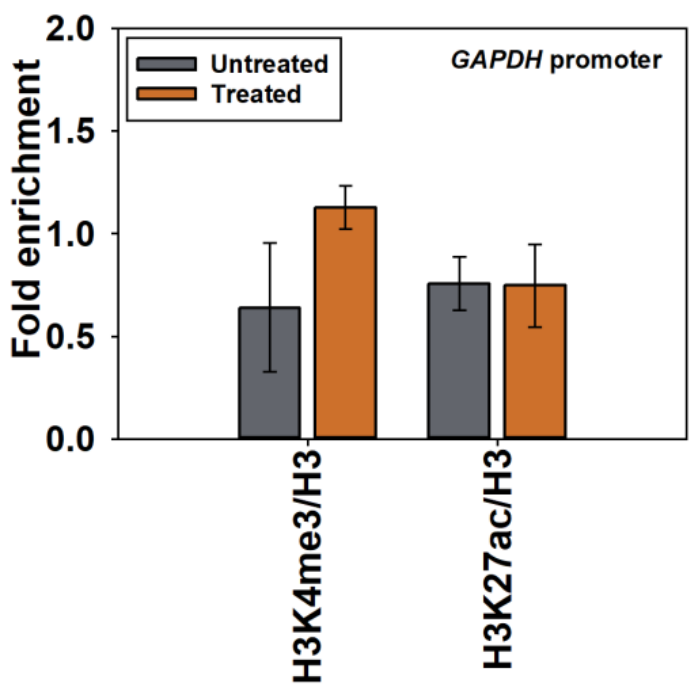


Figure 6

A

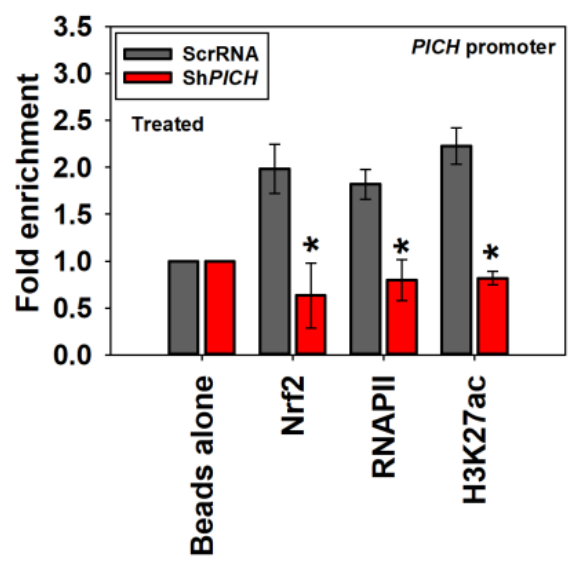

E

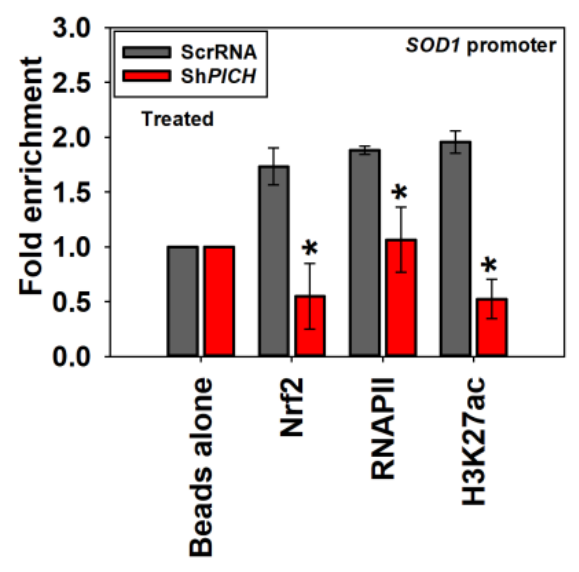

B

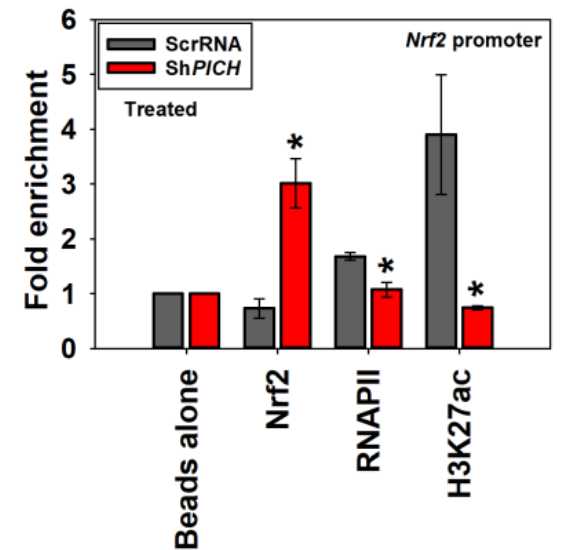

F

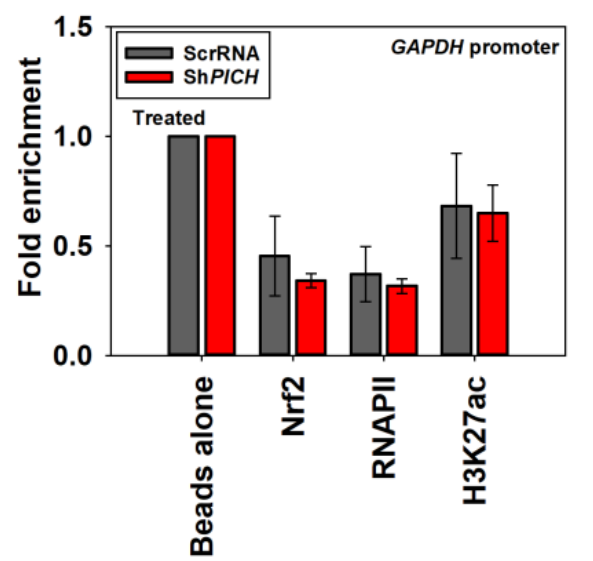

C
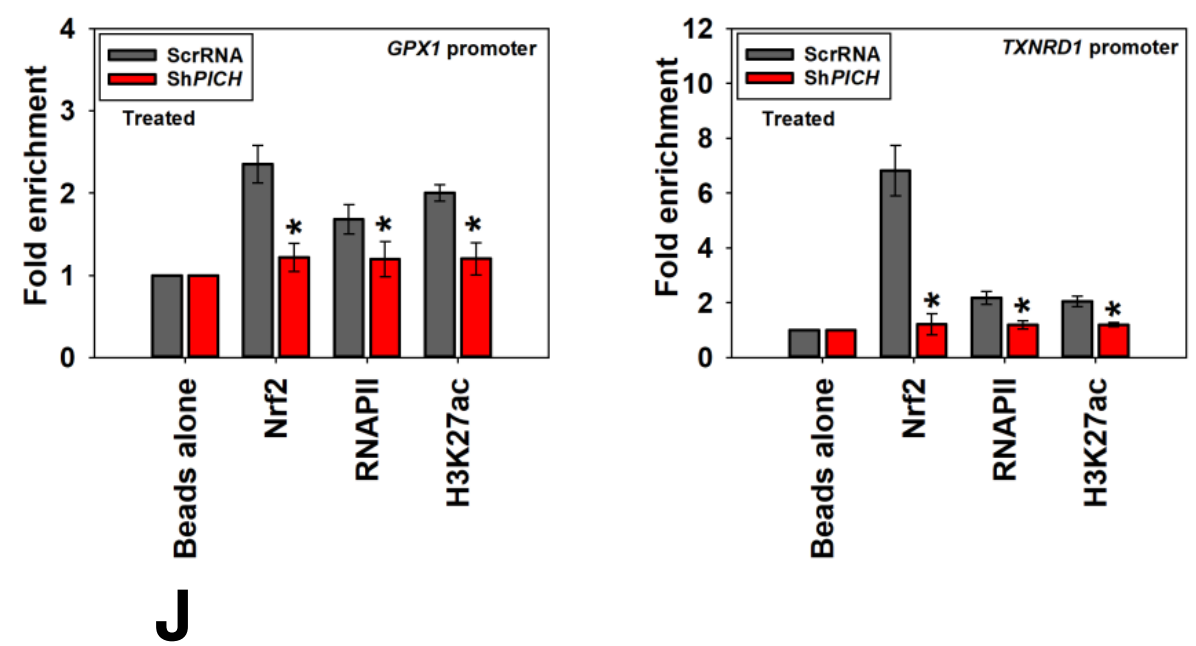

G

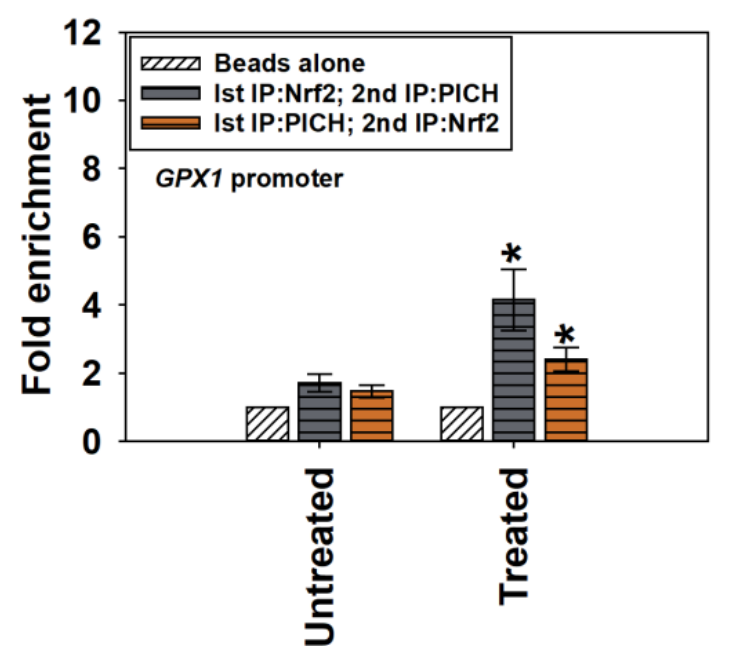

H

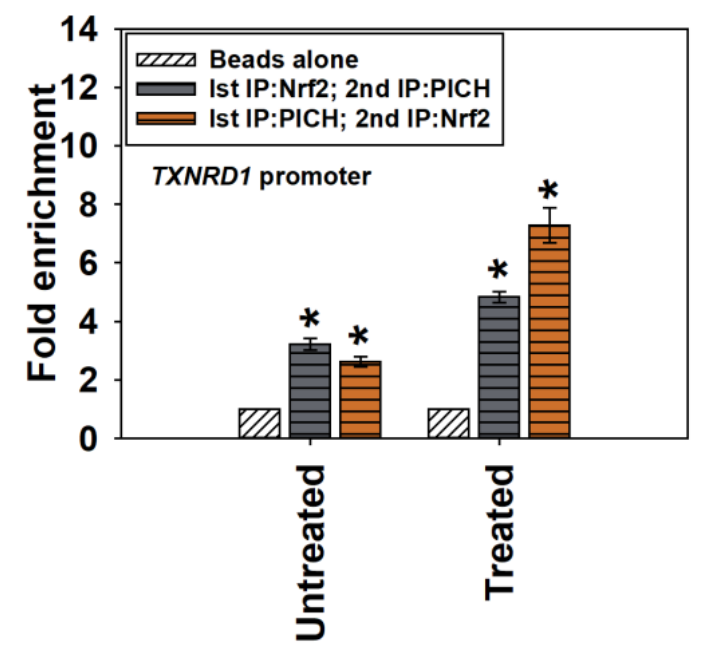

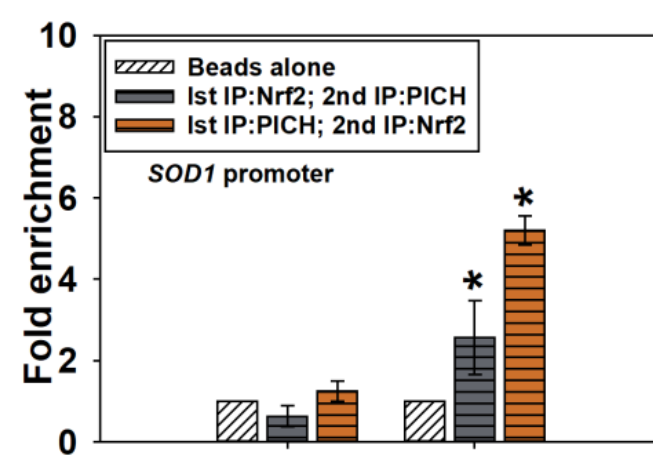

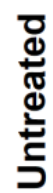

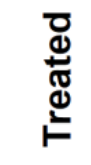

$180 \mathrm{kDa}$

$100 \mathrm{kDa}$

IB: H3K27ac 
Figure 7

A

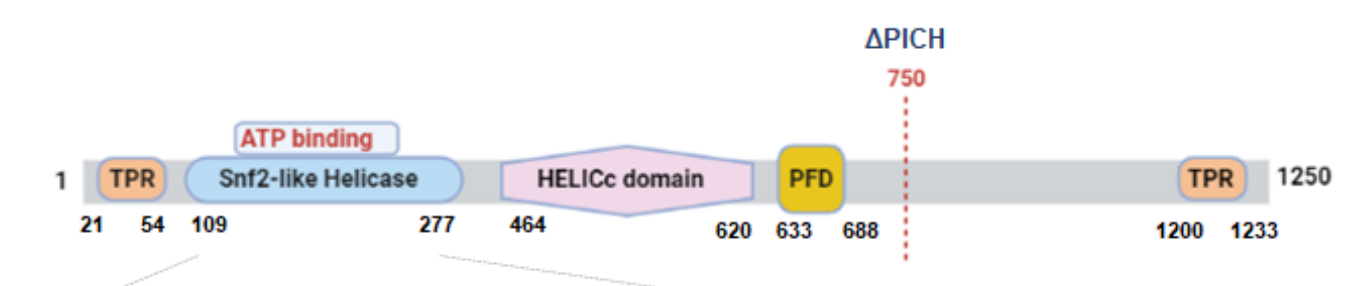

128

LYRDGRKGGILADDMGLGKTVQIIAFLSGMFDAS.

LYRDGRKGGILADDMGLGATSVQIIAFLSGMFDA.

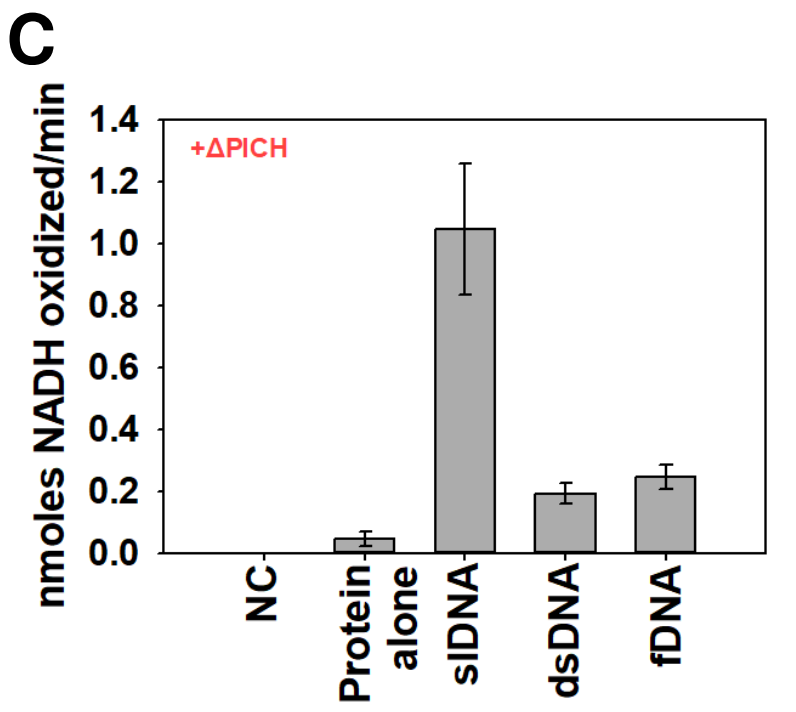

F

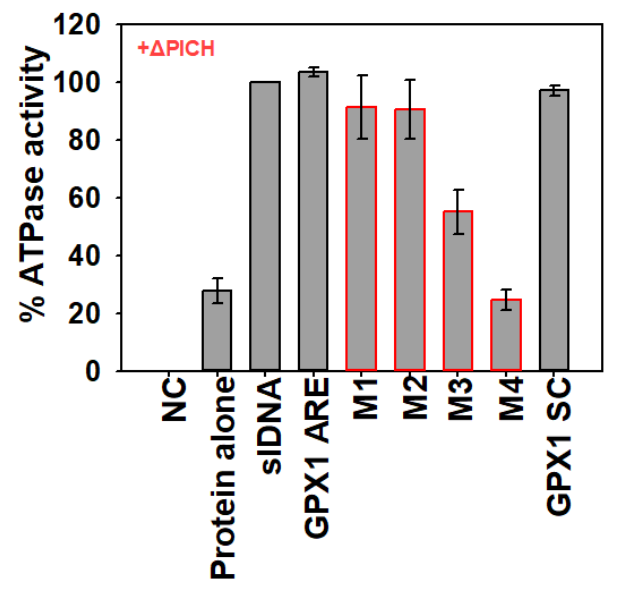

ELWSLFDFACQG

$\triangle \mathrm{PICH}$ ELWSLFDFACQG

$\triangle \mathrm{PICHK} 128 \mathrm{~A}$

B Marker Protein

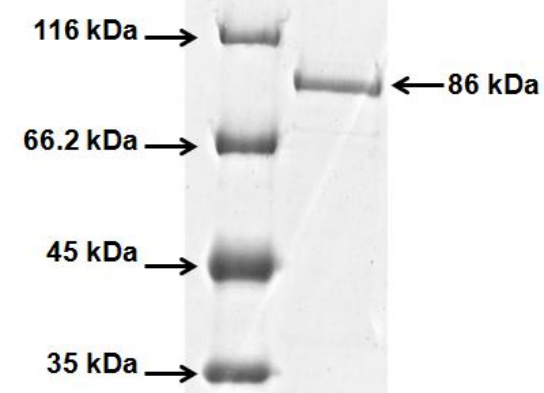

E

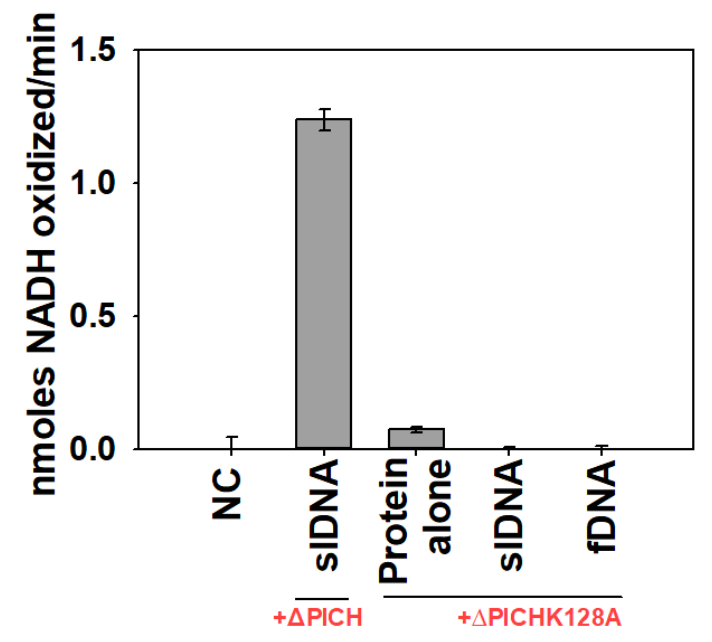

G

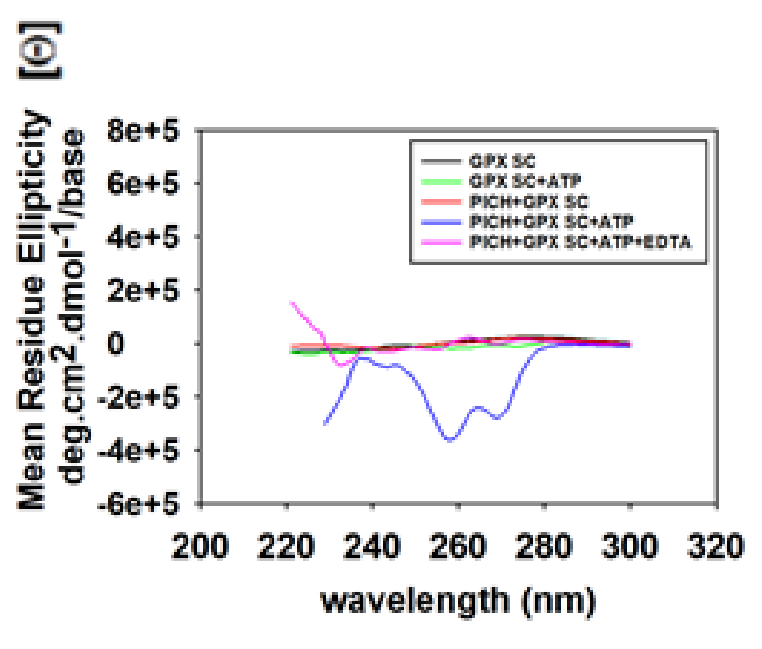

H

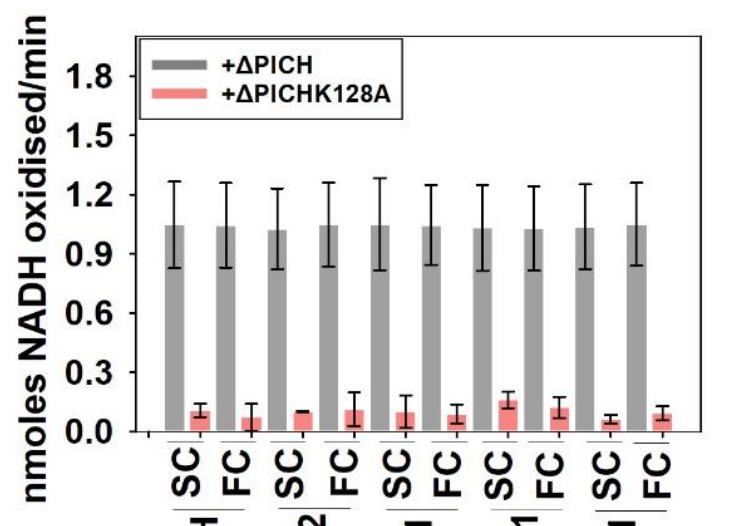

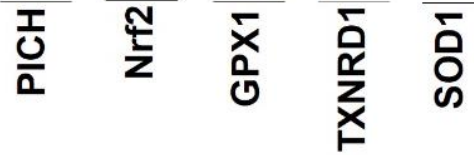

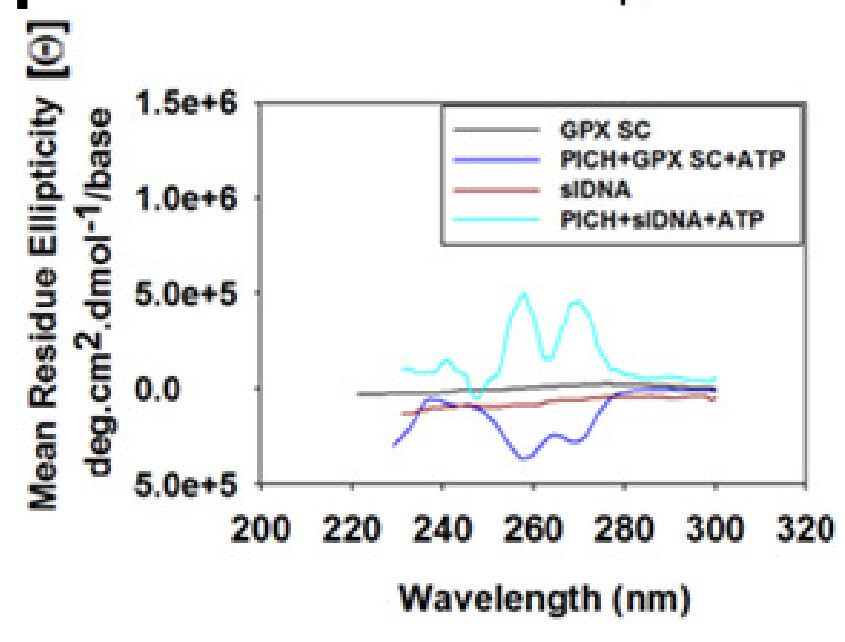

